\title{
Investigating the Dynamics of Elk Population Size and Body Mass in a Seasonal Environment Using a Mechanistic Integral Projection Model
}

\author{
Shelly Lachish, ${ }^{1, \star}$ Ellen E. Brandell, ${ }^{2}$ Meggan E. Craft, ${ }^{3}$ Andrew P. Dobson, ${ }^{4}$ Peter J. Hudson, ${ }^{2}$ \\ Daniel R. MacNulty, ${ }^{5}$ and Tim Coulson ${ }^{1}$
}

1. Department of Zoology, University of Oxford, Zoology Research and Administration Building, 11a Mansfield Road, Oxford OX13SZ, United Kingdom; 2. Center for Infectious Disease Dynamics and Department of Biology, Huck Institute of the Life Sciences, Pennsylvania State University, University Park, Pennsylvania 16802; 3. Department of Veterinary Population Medicine, University of Minnesota, Saint Paul, Minnesota 55108; 4. Department of Ecology and Evolutionary Biology, Eno Hall, Princeton University, Princeton, New Jersey 08540; 5. Department of Wildland Resources and Ecology Center, Utah State University, Logan, Utah 84341

Submitted May 23, 2019; Accepted December 11, 2019; Electronically published June 22, 2020

Online enhancements: supplemental tables and figures, $\mathrm{R}$ code.

AвSTRACT: Environmentally mediated changes in body size often underlie population responses to environmental change, yet this is not a universal phenomenon. Understanding when phenotypic change underlies population responses to environmental change is important for obtaining insights and robust predictions of population dynamics in a changing world. We develop a dynamic integral projection model that mechanistically links environmental conditions to demographic rates and phenotypic traits (body size) via changes in resource availability and individual energetics. We apply the model to the northern Yellowstone elk population and explore population responses to changing patterns of seasonality, incorporating the interdependence of growth, demography, and density-dependent processes operating through population feedback on available resources. We found that small changes in body size distributions can have large impacts on population dynamics but need not cause population responses to environmental change. Environmental changes that altered demographic rates directly, via increasing or decreasing resource availability, led to large population impacts in the absence of substantial changes to body size distributions. In contrast, environmentally driven shifts in body size distributions could occur with little consequence for population dynamics when the effect of environmental change on resource availability was small and seasonally restricted and when strong density-dependent processes counteracted expected population responses. These findings highlight that a robust understanding of how associations between body size and demography influence population responses to environmental change will require knowledge of

* Corresponding author; email: shellstar@gmail.com.

ORCIDs: Lachish, https://orcid.org/0000-0003-1886-6454; Craft, https:// orcid.org/0000-0001-5333-8513; Dobson, https://orcid.org/0000-0002-9678-1694; Coulson, https://orcid.org/0000-0001-9371-9003.

Am. Nat. 2020. Vol. 196, pp. E23-E45. (C) 2020 by The University of Chicago. 0003-0147/2020/19602-59267\$15.00. All rights reserved.

DOI: $10.1086 / 708723$ the shape of the relationship between phenotypic distributions and vital rates, the population status with regard to its carrying capacity, and importantly the nature of the environmentally driven change in body size and carrying capacity.

Keywords: population dynamics, phenotype-demography associations, body size, bioenergetics, environmental change, Yellowstone.

\section{Introduction}

Understanding the consequences of changing environmental conditions for population growth and persistence is a core focus of modern ecology, yet our ability to predict how populations will respond to environmental change remains poor (Lawson et al. 2015). Empirical and theoretical work shows that environmental change can alter population abundance and growth rates either by changing vital rates (i.e., impacting directly on the survival and fecundity prospects of individuals) or by shifting the distribution of fitness-related phenotypic traits in the population, subsequently altering individual performance (i.e., impacting indirectly on demographic rates; Pelletier et al. 2007; Ozgul et al. 2012; Douhard et al. 2018). The latter is perhaps best exemplified by studies of body size-demography associations under changing environmental conditions (Ozgul et al. 2010). Body size is a good proxy for individual performance in many species (Peters 1986). Shifts in body size distributions can occur as a plastic response to different environmental regimes or in response to changing selection pressures (Via et al. 1995; Benton et al. 2006; Bradshaw and Holzapfel 2006). Regardless of the mechanism, a growing body of literature indicates that environmentally driven changes in body size distribution can drive changes in population dynamics (Benton et al. 2006; 
Ozgul et al. 2010; van Benthem et al. 2017; Hoy et al. 2018). For example, warmer spring air temperatures increased the length of the growing period for marmots, enabling them to emerge from hibernation earlier, wean their young earlier, and subsequently achieve greater body mass (Ozgul et al. 2010). As vital rates are strongly dependent on body mass in this species, the subsequent increase in survival rates resulted in a rapid population increase and altered population dynamics (Ozgul et al. 2010).

While environmentally mediated changes in body size may underlie population responses to environmental change in many circumstances, this is not a universal phenomenon (Isaac 2009; Pelletier et al. 2012; Gaillard et al. 2013; Colchero et al. 2019). Environmental change may lead to changes in population abundance that occur either alongside changes in population composition (i.e., the sizes of individuals present) or independently of these (Isaac 2009). Conversely, environmental change may alter population composition with little detectable change in population abundance (Mason et al. 2014). Understanding when and why each of these routes transpires is important because intraspecific variation in body size and densitydependent processes interact in complex ways to influence both population dynamics and the outcomes of interspecific interactions. For example, temporal variation in resource consumption is determined not only by population abundance but also by the distribution of body sizes within a population. Thus, environmentally driven changes in body size distributions can alter the strength of ecological interactions, potentially inducing or modifying feedback loops among population abundance, resource biomass, and trait dynamics (Bolnick et al. 2011; Hempson et al. 2015; Griffiths et al. 2018). In addition, environmentally driven shifts in body size can alter the balance of asymmetric interactions among individuals, which can have stabilizing or disruptive effects on population dynamics (Nelson et al. 2019), weaken the strength of trophic cascades (Detmer and Wahl 2019), or lead to emergent phenomena, such as Allee effects, facilitation, or predator exclusion (De Roos et al. 2003).

An additional concern for accurately predicting population responses to environmental change is that environmental change occurs as a multifaceted phenomenon composed of component parts that may act in conflicting ways. In temperate environments, for example, forecasts for altered patterns of seasonality under future climate scenarios include rising temperatures, altered precipitation patterns, increasing fluctuations in the frequency and severity of extreme events, and changes to the timing, depth, and extent of seasonal snow cover (IPCC 2013). Each of these processes can modify the amount and quality of seasonal vegetation in different and potentially contrasting ways, thus exerting both synergistic and antagonistic effects on resource availability and productivity. For most tem- perate vertebrate species, demographic rates often increase with spring-summer productivity and decrease with winter severity (Sæther 1997; Coulson et al. 2001). Hence, this complicates our ability to predict population responses to environmental change when multiple conflicting processes act to modify patterns of resource availability (PearceHiggins et al. 2015). To address this problem, ecologists require knowledge of how distinct environmental processes affect demographic rates, phenotypic trait distributions, and population trajectories.

A mechanistic understanding of how environmental change alters resource availability and body size-demography associations - and how these in turn affect trait distributions, individual performance, and ultimately population growth - would advance our ability to accurately predict how populations will respond to environmental change. To date, research in this area has predominately employed phenomenological approaches in nondynamic frameworks (e.g., Stenseth et al. 2004; Plard et al. 2015; van Benthem et al. 2017; Dubos et al. 2018). These approaches are valuable, but they ignore potential feedbacks among the environmental change, resource availability, growth trajectories, and population dynamics, and they do not afford insights into the mechanisms generating observed patterns. Moreover, given the pervasiveness of nonlinearity in most biological systems (Small 2012) and the substantial uncertainty surrounding environmental forecasts (IPCC 2013), predictions from phenomenological models will rarely be valid beyond the range of the data for which they were parameterized.

An alternative approach is to develop a dynamic population model that mechanistically links environmental conditions to changes in demographic rates and phenotypic traits (body size) via changes in resource availability and individual energetics. Integral projection models (IPMs) are a powerful tool to investigate population-level processes from an individual-level perspective, particularly for populations structured by continuous traits, such as body size (Coulson 2012; Merow et al. 2014). The generality of IPMs permits their application to any system for which there is available life-history and trait-specific data. In this article, we develop an IPM in which the demographic functions that determine population dynamics (i.e., growth, survival, and reproduction) are mechanistically obtained in a bioenergetic framework. The bioenergetic equations describe rates of resource acquisition, assimilation, and allocation as a function of individual physiology (body size, energy reserves, and breeding potential) and resource availability in a seasonal environment. In this way, the model captures the complex interplay between the dynamics of individual growth, which determine phenotypic trait distributions and demographic rates, and density-dependent processes operating through population feedback on available resources. 
Accordingly, the model enables us to explore population responses to environmental change while incorporating the interdependence of growth and demography and the densitydependent feedbacks that can regulate populations in variable environments.

Although generic in nature, we parameterized the model for a population of elk (Cervus canadensis) living in the northern part of Yellowstone National Park and the adjoining areas of Montana (hereafter, "northern Yellowstone"; MacNulty et al. 2016). We chose this system for several reasons. First, data are available on the demography, vital rates, and energetics of food consumption in elk to obtain sensible estimates for our model parameters. Second, like other large abundant ungulates, elk can have significant impacts on vegetation dynamics in grassland ecosystems and are often regarded as keystone species in the ecological communities of the Northern Rocky Mountains (Ripple et al. 2015; Starns et al. 2015; Frank et al. 2016). Third, this region is experiencing marked changes in environmental seasonality that are forecast to continue under current climate models: warmer spring-summer temperatures, longer vegetation growing season, more frequent drought, and shorter and less severe winters (Chang and Hansen 2014; Romme and Turner 2015). These environmental changes are likely to have consequences for this elk population, as variation in winter severity and spring productivity are correlated with some vital rates in this species (Cook et al. 2004; Eberhardt et al. 2007; Proffitt et al. 2014). At present, robust predictions for the consequences of such changes remain lacking. Finally, we parameterize our model for this system because it has been the focus of ongoing debate regarding the role of changing environmental factors (as described above) and changing species interactions (e.g., the recovery of large carnivores) in driving the recent decline of the northern Yellowstone elk population and generating more broad-scale ecosystem change (see, e.g., Vucetich et al. 2005; Ripple and Beschta 2006; Kauffman et al. 2010; MacNulty et al. 2016). We use our novel and generalizable model to (1) investigate the dynamics of simulated elk body and population sizes under a baseline seasonal environment; (2) examine how perturbations to key demographic and bioenergetic parameters influence elk population size, resource availability, and the distribution of structural mass and energy reserves in the elk population; and (3) investigate how changing patterns of seasonality alter the population size and population composition (i.e., body size distribution) of elk.

\section{Methods}

\section{General Model Structure}

We developed a single-sex bioenergetic IPM for a population of female herbivores consuming a dynamic re- source in a predator-free, seasonal environment. The model is formulated to reflect the ecology and population dynamics of elk feeding on a seasonally fluctuating temperate grassland and can be readily adapted to other systems. We assume an annual life history for elk, with time iterated forward on a monthly time step (i.e., 12 time steps, $t$, per year). The dynamics of the elk population are defined by an IPM that links changes in the distribution of individual phenotypes to demographic outcomes at the population level. We define the phenotype of the elk, $Z$, to be the sum of a structural mass component $Z_{\mathrm{S}}$ and an energy reserve mass component, $Z_{\mathrm{R}}\left(Z=Z_{\mathrm{S}}+Z_{\mathrm{R}}\right)$. The structural component contains bones and essential organs and cannot decrease over time. The energy reserve component is principally muscle and fat that is used for growth and investment in offspring and thus fluctuates over time. The IPM iterates the distribution of $Z$ from time $t, H(Z, t)$, to time $t+1, H\left(Z^{\prime}, t+1\right)$. The model states that

$$
\begin{aligned}
& H\left(Z^{\prime}, t+1\right) \\
& \quad=\int_{\Omega}\left[D\left(Z^{\prime} \mid Z, t\right) R(Z, t)+G\left(Z^{\prime} \mid Z, t\right) S(Z, t)\right] H(Z, t) d Z,
\end{aligned}
$$

where the survival function $S(Z, t)$ is the probability that an individual of mass $Z$ survives from time $t$ to $t+1$ and $G\left(Z^{\prime} \mid Z, t\right)$ is the probability that an individual of mass $Z$ at time $t$ grows to mass $Z^{\prime}$ at $t+1$, conditional on survival. The reproduction function $R(Z, t)$ gives the number of offspring produced between time $t$ and $t+1$ by an individual of mass $Z$ at time $t$ that recruit to the population. The probability density function $D\left(Z^{\prime} \mid Z, t\right)$ gives the probability that the offspring of an individual of mass $Z$ are of mass $Z^{\prime}$ at time $t+1$ and describes the development of the phenotype between time periods. These four functions are defined in detail below. The closed interval $\Omega$ denotes the domain for integration.

\section{Dynamics of the Resource}

Northern Yellowstone elk are primarily grazers, and grasses constitute $>75 \%$ of their winter diet (Christianson and Creel 2007). Accordingly, we assume a seasonal grassland environment where resources, $V$, grow during a 6-month growing season and do not grow during a 6-month nongrowing season. Over a month in the growing season the dynamics of the resource are described with a simple growth function:

$$
V_{t+1}=\left(1-a_{t}\right) V_{\max }+a_{t} V_{t}
$$

In the absence of elk and during months when the resource grows, at any starting point where $V_{t=1}<V_{\max }$ the dynamics of $V$ will asymptotically converge to $V_{\max }$ for values of $0<a<1$. During the nongrowing season 
the resource does not grow $(a=1)$, and snow can fall to cover the resource.

In bioenergetic models, the maximum ingestion rate of an organism is assumed to be proportional to its body surface area and scales according structural mass ${ }^{2 / 3}$ (see, e.g., Illius and O'Connor 2000; van der Meer 2006). Accordingly, the maximum ingestion rate of the elk scales following a two-thirds power law with structural mass $\left(Z_{\mathrm{S}}\right.$; Illius and O'Connor 2000). We also assume that consumption follows a type II functional response with resource biomass (Owen-Smith 2002). In addition, we include a check on overconsumption by modeling consumption as a sigmoid function of a target ratio of energy reserve to total size $\left(Z_{\mathrm{R}}: Z\right.$; De Roos et al. 2009). This limits resource consumption when individuals approach the target ratio. Hence, maximum monthly consumption is defined as

$$
C_{\max }\left(Z_{\mathrm{S}}\right)=\left(c Z_{\mathrm{S}}^{2 / 3}\right)\left(\frac{V_{t}}{\theta+V_{t}}\right)\left(\frac{1}{1+\exp \left(-\eta\left(f Z-Z_{\mathrm{R}}\right)\right)}\right),
$$

where $c$ is the slope of the power function, $\theta$ gives the halfsaturation constant in grazing rate, $\eta$ determines the steepness in satiation scaling of consumption rate, and $f$ is the target energy reserve mass as a fraction of total mass $(Z)$.

The distribution of $Z_{\mathrm{S}}$ in the elk population is defined as $H\left(Z_{S}, t\right)$. Consequently, the maximum rate of resource depletion by all elk in the population is $\int H\left(Z_{S}, t\right) C_{\max }\left(Z_{S}\right) d Z_{S}$. The population of elk cannot consume all of the resources. The value $V_{\text {min }}$ describes the lowest level the resource can be depleted to and represents the minimum sward height that the elk can graze. Accordingly, resource consumption is scaled by a constant $p$ that ensures that $V_{t+1}>V_{\min }$ :

$$
p=\left\{\begin{array}{cl}
0 & \text { when }\left(V_{t} \leq V_{\min }\right), \\
1 & \text { when }\left(V_{t}-\int H\left(Z_{\mathrm{s}}, t\right) C_{\max }\left(Z_{\mathrm{S}}\right) d Z_{\mathrm{s}}>V_{\min }\right), \\
\frac{V_{t}-V_{\min }}{\int H\left(Z_{\mathrm{s}}, t\right) C_{\max }\left(Z_{\mathrm{S}}\right) d Z_{\mathrm{S}}} & \text { when }\left(V_{t}-\int H\left(Z_{\mathrm{s}}, t\right) C_{\max }\left(Z_{\mathrm{S}}\right) d Z_{\mathrm{S}}<V_{\min }\right) .
\end{array}\right.
$$

Additionally, when snow falls it reduces the amount of resource that elk can consume by a constant proportion, $\varsigma$ (Fortin et al. 2005). The dynamics of the total resource can now be described as

$$
V_{t+1}=(1-a) V_{\max }+a V_{t}-\varsigma p \int H\left(Z_{\mathrm{S}}, t\right) C_{\max }\left(Z_{\mathrm{S}}\right) d Z_{\mathrm{S}}
$$

where $\varsigma=0.5$ when snow falls and 1 otherwise (see table 1 ).

\section{Elk Population Dynamics: Defining the IPM Functions}

Survival Function. We constructed a survival function to capture the main characteristics of the mortality schedule of wild elk-that is, lower mortality rates for smaller (younger) elk and very high survival rates for fully grown elk (adults). We assume that mortality is phenotype dependent and use a logit function to model $S(Z, t)$ as a function of total mass, $Z$. In addition, we assume that death occurs as a function of the ratio of energy reserve to total mass $\left(Z_{\mathrm{R}} / Z\right)$, with individuals dying when reserves drop below a threshold ratio, $b$. This formulation captures the fact that weak individuals can die from multiple causes (e.g., starvation, disease). Survival is thus specified as

$$
S(Z, t)=\left\{\begin{array}{cc}
0 & \text { if }\left(\frac{Z_{\mathrm{R}}}{Z}<b\right), \\
\frac{1}{1+\exp \left(-\left(\beta_{0}+\beta_{1} Z+\cdots\right)\right)} & \text { if }\left(\frac{Z_{\mathrm{R}}}{Z} \geq b\right),
\end{array}\right.
$$

where $\beta_{0}$ and $\beta_{1}$ are the intercept and slope of the logit function and the centered horizontal ellipsis represents other factors that influence survival and could be incorporated if desired (e.g., predation, disease).

Growth Function. From the equations above, we see that the expected total resource consumed by any individual is $p C_{\max }\left(Z_{\mathrm{S}}\right)$. The expected amount of assimilated energy is then $j p C_{\max }\left(Z_{\mathrm{s}}\right)$, where $j$ is the energy content of the resource. A portion of this assimilated energy is, subsequently, allocated to maintenance. In this way, our model is analogous to a simplified net production model, in which a portion of assimilated energy is first allocated to maintenance costs, with the remainder (the net production, or the difference between energy acquisition and maintenance) partitioned between growth and reproduction (Lika and Nisbet 2000). Monthly maintenance costs are obtained from daily metabolic costs and are assumed to scale following a three-quarters power law with total body mass $(Z)$. This allometric scaling of metabolic rate with mass (known as Kleiber's law) is a consequence of the scaling of resource supply networks and exchange surfaces in branching hierarchical networks, arising from the physics and geometry of animal circulatory systems (Savage et al. 2004):

$$
M(Z)=30 \cdot \delta Z^{3 / 4}
$$

The amount of energy then available for growth or reproduction over a month is

$$
\Delta E(Z)=j p C_{\max }\left(Z_{\mathrm{s}}\right)-M(Z) .
$$

This is added to an individual's energy reserves:

$$
Z_{\mathrm{R}}^{\circ}=Z_{\mathrm{R}}+m^{-1} \Delta E(Z),
$$

where the parameter $m$ is the metabolic coefficient for the conversion between assimilated energy and energy reserve 
and varies between anabolic (positive $\Delta E(Z)$ ) and catabolic conditions (negative $\Delta E(Z)$; Illius and O'Connor 2000).

Once individuals have attained a structural mass that is equal to or greater than a threshold $(k)$, they cease to grow bigger (although they continue to gain and lose energy reserve mass). At each time interval, individuals that are below this structural mass threshold, $Z_{\mathrm{S}}<k$, grow by turning a proportion, $\psi$, of their stored resources into $Z_{\mathrm{S}}$, subsequently depleting their stored resources. Energy reserves are converted to structural components with constant efficiency, $\varepsilon_{1}$. Individuals that are above this threshold, $Z_{\mathrm{S}} \geq k$, simply accumulate energy reserves (at the same massdependent rate as smaller individuals). Hence, we can define the expected distributions of $Z_{\mathrm{S}}$ and $Z_{\mathrm{R}}$ at $t+1$ (in nonbreeding months) thus:

$$
\begin{aligned}
& Z_{\mathrm{S}}^{\prime}=\left\{\begin{array}{cc}
Z_{\mathrm{S}}+\psi \varepsilon_{1} Z_{\mathrm{R}}^{\circ} & \text { if }\left(Z_{\mathrm{S}} \leq k\right), \\
Z_{\mathrm{S}} & \text { if }\left(Z_{\mathrm{S}}>k\right) ;
\end{array}\right. \\
& Z_{\mathrm{R}}^{\prime}=\left\{\begin{array}{cc}
(1-\psi) Z_{\mathrm{R}}^{\circ} & \text { if }\left(Z_{\mathrm{S}} \leq k\right), \\
Z_{\mathrm{R}}^{\circ} & \text { if }\left(Z_{\mathrm{S}}>k\right) .
\end{array}\right.
\end{aligned}
$$

During the annual breeding event (the breeding month, in which all reproductive costs are incurred), individuals that have reached the required size for breeding $\left(Z_{\mathrm{S}}=k\right)$ will breed provided they have accumulated sufficient energy reserves (see details below). We refer to this group as "potential breeders." We assume that potential breeders (individuals with $Z_{\mathrm{S}} \geq k$ ) will breed if the ratio of their energy reserve mass to total mass is greater than the threshold value, $g\left(Z_{\mathrm{R}}^{\circ}: Z>g\right.$. Those that breed allocate a proportion, $\tau$, of their stored resources to producing and provisioning offspring. Thus, over the time interval in which reproduction occurs, changes in $Z_{\mathrm{R}}$ are defined thus:

$$
Z_{\mathrm{R}}^{\prime}=\left\{\begin{array}{cl}
(1-\psi) Z_{\mathrm{R}}^{\circ} & \text { if }\left(Z_{\mathrm{S}} \leq k\right), \\
Z_{\mathrm{R}}^{\circ} & \text { if }\left(Z_{\mathrm{S}}>k \text { and } Z_{\mathrm{R}}^{\circ}: Z \leq g\right), \\
(1-\tau) Z_{\mathrm{R}}^{\circ} & \text { if }\left(Z_{\mathrm{S}}>k \text { and } Z_{\mathrm{R}}^{\circ}: Z>g\right) .
\end{array}\right.
$$

If we assume that the probability distribution of phenotypic values at $t+1$ for any given phenotype at $t$ is Gaussian, then the general probability density function describing growth (in $Z_{\mathrm{S}}$ or $Z_{\mathrm{R}}$ ) is given by

$$
G\left(X^{\prime} \mid X, t\right)=N\left(\mu_{X}, \sigma_{X}^{2}\right)=\frac{1}{\sqrt{2 \pi \sigma_{X}^{2}}} \exp \left(\frac{-\left(X^{\prime}-\sigma_{X}^{2}\right)^{2}}{2 \sigma_{X}^{2}}\right),
$$

where $X$ is either $Z_{\mathrm{S}}$ or $Z_{\mathrm{R}}$. Here, $N$ is a normal distribution with a given mean, $\mu$, that is defined from the respective el- ement of equations (10), (11), or (12). For example, for $G\left(Z_{\mathrm{S}}^{\prime} \mid Z_{\mathrm{S}}, t\right), \mu=Z_{\mathrm{S}}+\psi \varepsilon_{1} Z_{\mathrm{R}}^{\circ}$ when $Z_{\mathrm{S}} \leq k$, and $\mu=Z_{\mathrm{S}}$ when $Z_{\mathrm{S}}>k$. Likewise, during the breeding month, for $G\left(Z_{\mathrm{R}}^{\prime} \mid Z_{\mathrm{R}}, t\right), \mu=\left(1-\tau Z_{\mathrm{R}}^{\circ}\right)$ for those individuals that breed. The size-dependent variance term, $\sigma^{2}$, is defined equivalently for the $G\left(Z_{\mathrm{S}}^{\prime} \mid Z_{\mathrm{S}}, t\right)$ and $G\left(Z_{\mathrm{R}}^{\prime} \mid Z_{\mathrm{R}}, t\right)$ functions as

$$
\sigma_{X^{\prime}}^{2}=9-e^{-\gamma X}
$$

where $X$ is either $Z_{\mathrm{S}}$ or $Z_{\mathrm{R}}$ and $\vartheta$ and $\gamma$ respectively define the intercept and coefficient of the function. This variance function captures variation in the acquisition of resources between individuals with the same phenotypic value and variation in the efficiency with which individuals convert resources into structural size or energy reserve (e.g., as a function of age, dominance, or genetic factors).

Reproduction Function. Breeding occurs annually over a single time step, such that all reproductive costs to individuals (i.e., costs of pregnancy, parturition, and lactation) are incurred over 1 month. As elk do not usually breed in their first year of life, we set a threshold size for breeding in the model equal to the minimum weight of yearling female breeders across several elk populations (140 kg; Cook et al. 2013). Individuals must be above this threshold structural size to breed but only do so if they have accumulated sufficient energy reserves. This condition describes the reproductive process typical of capital breeders (such as large ungulates), where reproduction is only possible given sufficient stored resources and where those resources were acquired before rather than during the breeding period (Stephens et al. 2009). Litter size can be considered a generalizable function: $L(m)$, where the value of $m$ indicates the maximum number of offspring. We assume a litter size of 1 for all breeders $(m=1)$, with a proportion, $\omega$, of young suffering immediate mortality. Hence,

$$
R(Z, t)=\left\{\begin{array}{cl}
0 & \text { if }\left(Z_{\mathrm{S}} \leq k\right) \text { or }\left(Z_{\mathrm{S}}>k \text { and } Z_{\mathrm{R}}^{\circ}: Z \leq g\right) \\
1-\omega & \text { if }\left(Z_{\mathrm{S}}>k \text { and } Z_{\mathrm{R}}^{\circ}: Z>g\right) .
\end{array}\right.
$$

Development Function. The development function defines investment in offspring and describes the association between parent and offspring phenotypic values. From the growth equations defined above, we see that mothers assign $\tau Z_{\mathrm{R}}^{\circ}$ of their resources to producing and provisioning offspring. A portion of this energy, $v$, goes to form offspring structural size, and the remainder $(1-v)$ goes to offspring energy reserves. A mother's energy reserves are converted to structural components in the offspring with a constant efficiency, $\varepsilon_{2}$, and to energy 


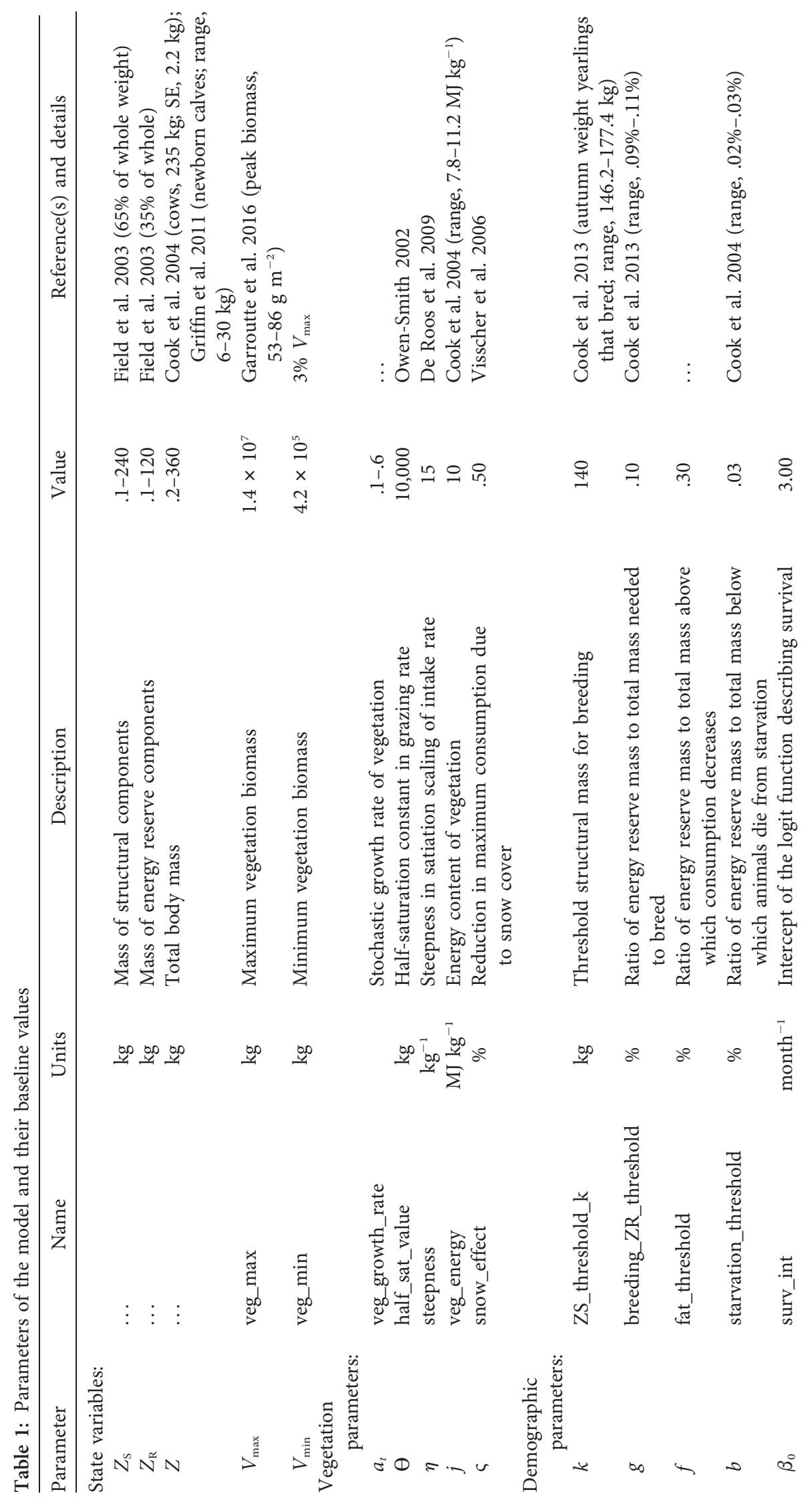

This content downloaded from 129.123.124.117 on July 21, 2020 11:34:26 AM 

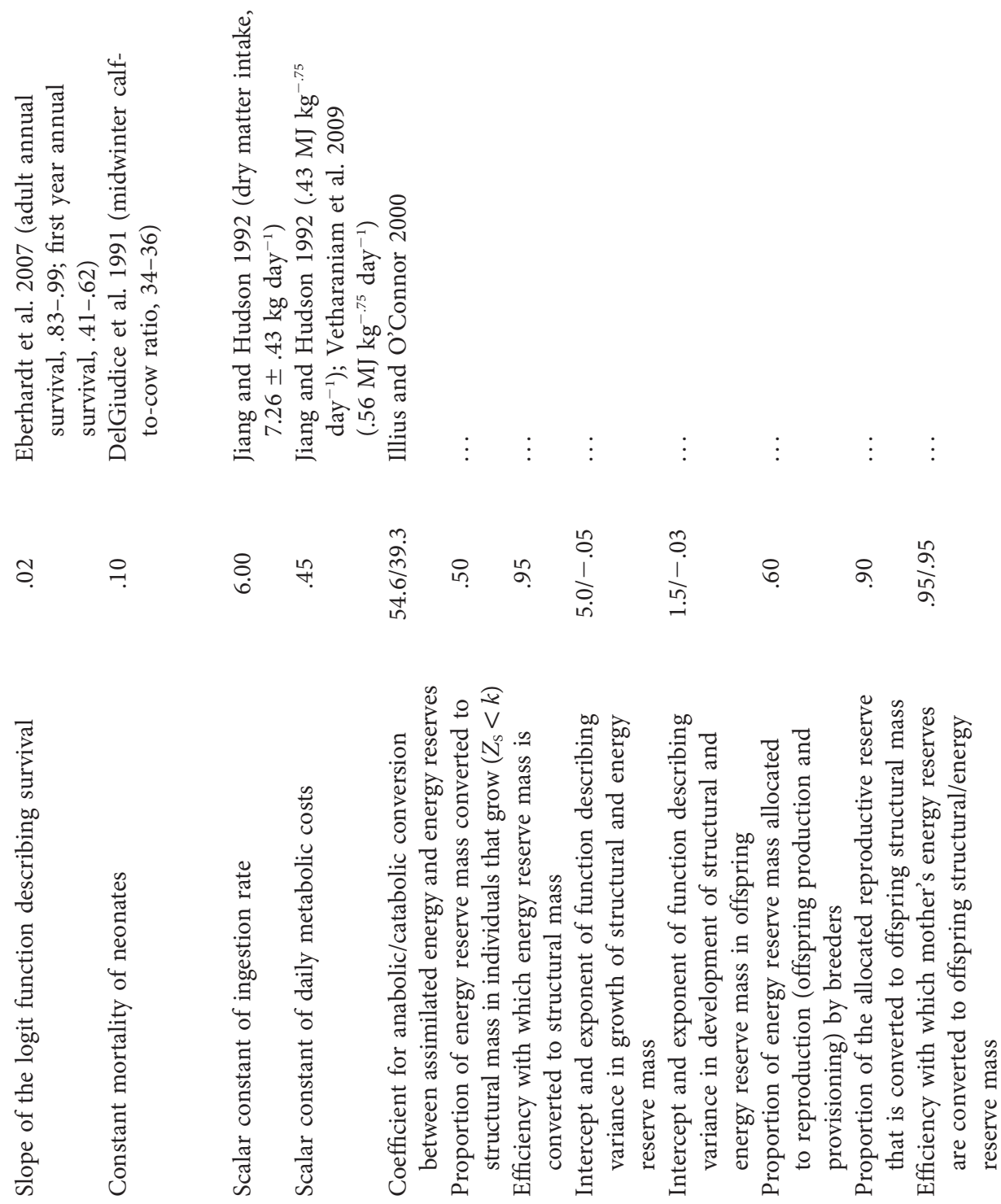

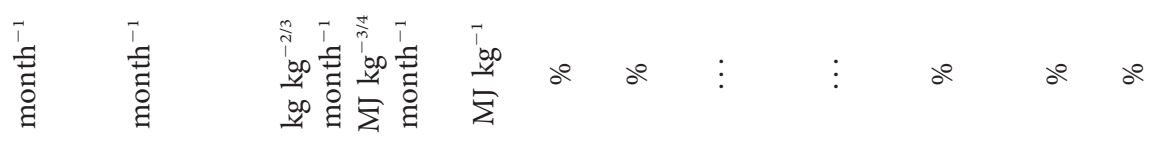

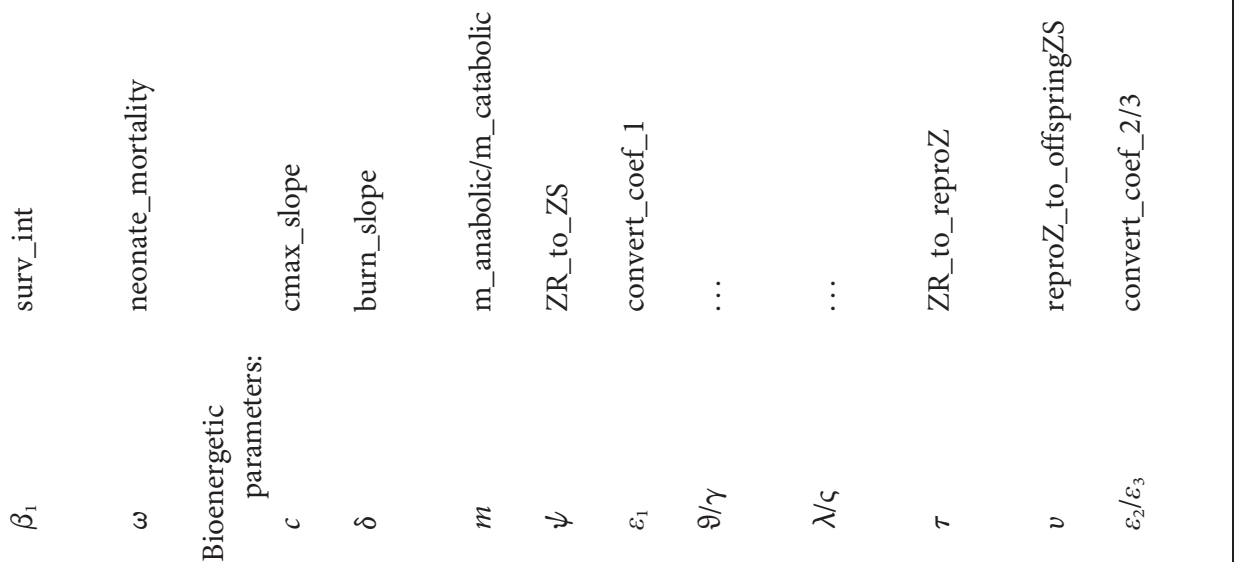

This content downloaded from 129.123.124.117 on July 21, 2020 11:34:26 AM 
reserves in her offspring with efficiency $\varepsilon_{3}$. Hence, we can define the expected development of $Z_{\mathrm{S}}$ and $Z_{\mathrm{R}}$ in offspring thus:

$$
\begin{aligned}
& Z_{\mathrm{S}_{\text {offspring }}}^{\prime}= \\
& \left\{\begin{array}{cl}
0 & \text { if }\left(Z_{\mathrm{S}} \leq k\right) \text { or }\left(Z_{\mathrm{S}}>k \text { and } Z_{\mathrm{R}}^{\circ}: Z \leq g\right), \\
v \cdot \varepsilon_{2} \cdot \tau \cdot Z_{\mathrm{R}}^{\circ} & \text { otherwise; }
\end{array}\right.
\end{aligned}
$$

$$
\begin{aligned}
& Z_{\mathrm{R}_{\text {offspring }}}^{\prime}= \\
& \left\{\begin{array}{cl}
0 & \text { if }\left(Z_{\mathrm{S}} \leq k\right) \text { or }\left(Z_{\mathrm{S}}>k \text { and } Z_{\mathrm{R}}^{\circ}: Z \leq g\right), \\
(1-v) \cdot \varepsilon_{3} \cdot \tau \cdot Z_{\mathrm{R}}^{\circ} & \text { otherwise. }
\end{array}\right.
\end{aligned}
$$

We then apply the same rationale used to construct the growth functions above to construct the development functions $\left(D\left(Z_{\mathrm{S}}^{\prime} \mid Z_{\mathrm{S}}, t\right)\right.$ and $\left.D\left(Z_{\mathrm{R}}^{\prime} \mid Z_{\mathrm{R}}, t\right)\right)$ :

$$
D\left(X^{\prime} \mid X, t\right)=N\left(\mu_{X}, \sigma_{X}^{2}\right)=\frac{1}{\sqrt{2 \pi \sigma_{X}^{2}}} \exp \left(\frac{-\left(X^{\prime}-\mu_{X}\right)^{2}}{2 \sigma_{X}^{2}}\right),
$$

where $X$ is either $Z_{\mathrm{S}}$ or $Z_{\mathrm{R}}$ and $N$ is a normal distribution with a given mean, $\mu$, defined from the respective element of equation (16) or (17). As above, the size-dependent variance, $\sigma^{2}$, is defined equivalently for the $D\left(Z_{\mathrm{S}}^{\prime} \mid Z_{\mathrm{S}}, t\right)$ and $D\left(Z_{\mathrm{R}}^{\prime} \mid Z_{\mathrm{R}}, t\right)$ functions and captures variation in how individuals convert resources into structural size or energy reserves in their offspring:

$$
\sigma_{X^{\prime}}^{2}=\lambda-e^{-\varsigma X},
$$

where $\lambda$ and $\varsigma$ respectively define the intercept and coefficient of the function.

\section{Model Parameterization}

Northern Yellowstone includes the valleys of the upper Yellowstone, Lamar, and Gardiner Rivers and comprises habitat within Yellowstone National Park and the adjoining areas of Montana. Sagebrush-grassland steppe is the predominant vegetation type, accounting for slightly more than half of all the nonforested vegetation and providing most of the forage for the large number of grazing animals that winter there: elk, bighorn sheep (Ovis canadenis), bison (Bison bison), mule deer (Odocoileus hemionus), and pronghorn (Antilocapra Americana; Houston 1982; Garroutte et al. 2016). Elk remain the most abundant wild ungulate within northern Yellowstone despite a large recent population decline, which has been variously attributed to increased predation pressure, prolonged periods of drought, and regulated hunting (Vucetich et al. 2005; Eberhardt et al. 2007; Proffitt et al. 2014). While the numbers and biomass of other herbivores in northern Yellowstone is relatively insignificant compared with that of elk, bison (which can weigh up to eight times an elk) have greatly increased in numbers in recent years (Frank et al. 2016). The model we present here is for Yellowstone before the bison population expansion.

As our model is nonspatial and because the dynamics of seasonal migration in northern Yellowstone elk are complex (with substantial individual heterogeneity in both migration distance and direction; White et al. 2010), we made the simplifying assumption that the simulated elk population was resident year-round. On the basis of an estimate of the mean phytomass in sagebrush-grassland ecotypes, we set $V_{\max }=1.4 \times 10^{7}$ and allowed the elk population to potentially consume all but $3 \%$ of it $\left(V_{\min }=4.2 \times 10^{5}\right.$; table 1; Garroutte et al. 2016). We allowed for temporal variation in resource growth rate by allowing $a$ to vary stochastically with time $\left(a_{t}\right)$, initially setting this to reflect faster growth (and subsequently investigating the effect of slower resource growth rates; see "Seasonality Analysis: Investigating the Influence of Changing Patterns of Seasonality on Model Outputs"). We made the simplifying assumption that the nutritional quality of the resource did not vary within or between seasons and set this parameter to reflect highquality forage (table 1). Although environmentally induced changes in plant quality may be an additional determinant of consumer body size (Christianson and Creel 2009; Parker et al. 2009; Smith-Ramesh et al. 2018), predicting how environmental change will alter plant phenology and quality is not straightforward, as changes to plant quality and phenology under different moisture and temperature regimes can be complex and context dependent (Smith-Ramesh et al. 2018). We incorporated winter snowfall probabilistically by allowing snow to fall for either two, three, or four consecutive months of the nongrowing season (with a probability of $0.2,0.4$, and 0.4 , respectively). This reflected the average number of months in which snow depth is on average $>10 \mathrm{~cm}$ across northern Yellowstone, thus restricting forage consumption by elk (based on data from SNOTEL sites; US Department of Agriculture, Natural Resources Conservation Service). On the basis of values from the literature, we capture the effects of both the depth and the density of the snow pack on forage availability by including a single parameter that proportionally reduced maximum consumption on months when snow fell (table 1).

Adult female elk weigh on average $235 \mathrm{~kg}$ (Cook et al. 2004). On the basis of hunting records we estimated the nonstructural mass of elk to be $35 \%$ of whole weight (Field et al. 2003). To avoid unintentional eviction of individuals from the matrix approximation of the IPM kernel, it is necessary to extend beyond observed phenotypic ranges (Williams et al. 2012). We created a vector of 50 structural size phenotypes $\left(Z_{\mathrm{S}}\right)$ ranging from 0.1 to 240 , each of which was associated with one of 50 energy 
Table 2: Details of model parameters varied 5\% or $10 \%$ lower or higher than their baseline value (BL) for sensitivity analysis

\begin{tabular}{llrrrrr}
\hline & & \multicolumn{3}{c}{ Parameter range } \\
\cline { 3 - 6 } Parameter & \multicolumn{1}{c}{ Name } & $<10 \%$ & $<5 \%$ & \multicolumn{1}{c}{ BL } & $>5 \%$ & $>10 \%$ \\
\hline$\delta$ & burn_slope & .405 & .428 & .450 & .473 & .495 \\
$c$ & cmax_slope & 5.400 & 5.700 & 6.000 & 6.300 & 6.600 \\
$f$ & fat_threshold & .270 & .285 & .300 & .315 & .330 \\
$\psi$ & ZR_to_ZS & .400 & .450 & .500 & .550 & .600 \\
$\beta_{0}$ & surv_int & 2.700 & 2.850 & 3.000 & 3.150 & 3.300 \\
$\beta_{1}$ & survslope & .018 & .019 & .020 & .021 & .022 \\
$\omega$ & neonate_mortality & .000 & .050 & .100 & .150 & .200 \\
$\tau$ & ZR_to_reproZ & .540 & .570 & .600 & .630 & .660 \\
$v$ & reproZ_to_offspringZS & .810 & .855 & .900 & .945 & Not run \\
\hline
\end{tabular}

reserve size phenotypes $\left(Z_{\mathrm{R}}\right)$ ranging from 0.1 to 120 , resulting in 2,500 possible phenotypes $(Z)$. Hence, the matrix approximation of the IPM consisted of a 2,500 $\times 2,500$ matrix describing transition rates from phenotypes at time $t$ to each possible class at $t+1$ (The $\mathrm{R}$ code scripts to define the model and run simulations are provided in a zip file, available online, as well as on GitHub at https://doi.org /10.5281/zenodo.2685071.) ${ }^{1}$ The initial population vector used to run the baseline model and simulations included only individuals with phenotypes within the narrower observed ranges (for $Z_{S}, 10-180$; for $Z_{R}, 3-80$ ). We set the threshold structural size beyond which growth ceases equal to the threshold size needed to breed (140 kg; table 1). Estimates of calf-cow ratios for northern Yellowstone elk in midwinter (6-7 months after birth) prior to large carnivore recovery were $\sim 35$ calves per 100 adult females (DelGiudice et al. 1991). Accordingly, we set the reproductive rate to 90 newborn calves for every 100 breeders (neonate mortality, $10 \%$; table 1 ), to account for oversummer mortality in the absence of predators (Griffin et al. 2011; Foley et al. 2015). On the basis of values from the literature, maximum consumption was parameterized such that individuals could potentially consume between $1.2 \mathrm{~kg}$ (newborn calves) and $7.8 \mathrm{~kg}$ of vegetation per day (full grown adult), while metabolic costs ranged from 3.0 $\mathrm{MJ} \mathrm{day}^{-1}$ (newborn calves) to $26.5 \mathrm{MJ} \mathrm{day}^{-1}$ (full-grown adults; see table 1).

Values of the remaining demographic and bioenergetic parameters were obtained from the literature or set to values informed by knowledge of related species (table 1). On the basis of the preliminary analysis, we ran the baseline model for 250 years from an initial population of 10,000 individuals and an initial vegetation biomass of 1,000,000 kg. Transient dynamics were discarded by only analyzing metrics over the final 200 years of the simulation.

1. Code that appears in The American Naturalist is provided as a convenience to readers. It has not necessarily been tested as part of peer review.

\section{Sensitivity Analysis: Investigating the Influence of Perturbations to Bioenergetic and Demographic Parameters on Model Outputs}

We conducted a sensitivity analysis to explore the sensitivity of model outputs to input parameters, focusing our sensitivity analysis on nine key bioenergetic and demographic parameters (table 2). Parameters chosen for the sensitivity analysis were those known to be important in the dynamics of large herbivores (survival parameters; Gaillard et al. 1998) and those for which we had little idea of the baseline value, as there are few estimates available from the literature (bioenergetics and development parameters). We conducted local sensitivity analysis by perturbing parameter values by very small amounts. However, to further explore why the model gave the predictions it did and to explore the influence of parameters for which we did not have good estimates, we used significantly larger perturbations of $\pm 5 \%$ and $\pm 10 \%$ of the parameter's value. We independently perturbed parameters while holding all other parameters constant at their baseline values (see table 2). We did not run a simulation for a $10 \%$ increase in the value of $v$ (reproZ_to_offspringZS), which determines the proportion of a mother's allocated reproduction reserves that goes to offspring structural size, as this would have resulted in the production of offspring below the starvation threshold ( $b=0.03$; table 2). Each simulation was run as per the baseline model. We examined how each parameter perturbation influenced the abundance of the elk population, the availability of resources, and the underlying distribution of structural and energy reserve sizes in the population.

\section{Seasonality Analysis: Investigating the Influence of Changing Patterns of Seasonality on Model Outputs}

We assessed how changes to patterns of seasonality affect the dynamics of our elk population by creating four variants of our baseline temperate season (table 3). These variants encapsulated the seasonal changes predicted to occur 
Table 3: Parameter details for the baseline season values (BL) and simulated seasonal variants

\begin{tabular}{lcccc}
\hline Season type & $\begin{array}{c}\text { Length of growing } \\
\text { period (months) }\end{array}$ & $\begin{array}{c}\text { Vegetation growth } \\
\text { rate (range) }\end{array}$ & $\begin{array}{c}\text { No. (probability) } \\
\text { snow months }\end{array}$ & $\begin{array}{c}\text { Reduction in consumption } \\
\text { during snow }(\%)\end{array}$ \\
\hline BL & 6 & Faster (.1-.6) & $2(.2), 3(.4)$, or $4(.4)$ & 50 \\
Longer season & 8 & BL & BL & BL \\
Lower productivity & $\mathrm{BL}$ & Slower $(.5-.9)$ & $\mathrm{BL}$ & $\mathrm{BL}$ \\
Fewer snow months & $\mathrm{BL}$ & $\mathrm{BL}$ & $1(.2), 2(.6)$, or 3 (.2) & $\mathrm{BL}$ \\
Less snowfall & $\mathrm{BL}$ & $\mathrm{BL}$ & $\mathrm{BL}$ & 20 \\
\hline
\end{tabular}

within the greater Yellowstone ecosystem (and more broadly in temperate ecosystems globally; IPCC 2013; Chang and Hansen 2014; Romme and Turner 2015). Our seasonal variants included an increase in the length of vegetation growing period ("Longer season"), a decrease in productivity during the growing season due to increased occurrence of drought ("Lower productivity"), shorter winters ("Fewer snow months"), and less severe winters ("Less snowfall"; see table 3 for details). As above, we ran each of the four seasonal variants as per the baseline model and examined how each variant influenced the abundance and biomass of the elk population, the availability of resources, and the underlying distribution of structural and energy reserve sizes in the population.

\section{Results}

\section{Elk Population Dynamics and Body Size Distributions under a Baseline Seasonal Environment}

Our baseline model, when parameterized for northern Yellowstone elk, predicted a population of approximately 20,000 elk (range, 11,691-27,522) that kept the vegetation below its maximum value and was periodically capable of grazing it down to its minimum value (fig. $1 a, 1 b$ ). The prebreeding abundance of approximately 15,000 individuals and a population of potential breeders (individuals with $Z_{\mathrm{S}} \geq k$ ) that varied between $\sim 11,000$ and $\sim 13,000$ elk is comparable to winter counts of elk obtained for this population prior to recovery of large carnivores, including the reintroduction of wolves (MacNulty et al. 2016). Predicted herbivore biomass from our model was approximately $30 \mathrm{~kg} \mathrm{ha}^{-1}$ (based on the mean biomass of the total elk population of $3,000,000 \mathrm{~kg}$; see figure S1 (figs. S1-S5 are available online)), which is very close to available estimates for herbivore biomass in northern Yellowstone prior to wolf reintroduction (Wagner 2006). Our model predicted that between $83 \%$ and $100 \%$ of potential breeders bred each year (fig. S2), which correlates well with estimates for this and other elk populations (pregnancy rates of 2-14-year-old females range from $78 \%$ to $93 \%$ in Rocky Mountain populations; Cook et al. 2013). In general, years in which fewer potential breeders bred followed periods of higher popula- tion abundance and lower vegetation biomass, although this only occurred beyond a threshold population size of $\sim 14,000$ individuals (fig. S3). This reveals that the simulated elk population was regulated at the system carrying capacity by density-dependent processes that limit reproductive output at high population densities via resource competition (figs. $1 a, 1 b$; S3). The mean overall rate of breeding in our model $(98.9 \%)$, however, was greater than that observed in northern Yellowstone elk (the observed pregnancy rate for prime-age northern Yellowstone elk was 91\% [95\% confidence interval, 0.87-0.94] prior to carnivore recovery; White et al. 2011). One explanation for this discrepancy is that while female elk mate each year, our model does not account for occasional in utero mortality of fetuses arising from genetic incompatibility between parents, developmental errors, or disease (Houston 1982).

Our model revealed distinct patterns of temporal variation in body size phenotypes in the population (fig. 1c). Among potential breeders (fig. $1 c$, breeders, red line), structural size $\left(Z_{\mathrm{S}}\right)$ varies relatively little annually, as individuals that have reached (or exceeded) the threshold size, $k$, cease to grow, while the size of their energy reserves varies greatly. The mean energy reserve size $\left(Z_{\mathrm{R}}\right)$ of potential breeders drops annually during the breeding month because of energy allocation to offspring production (fig. $1 c$, breeders, orange line). They regain these energy reserves rapidly as they consume food during the vegetation growing season and then face fluctuations in energy reserve size that are determined by feedbacks between population density and competition for limited resources (fig. $1 c$, breeders, orange line). On average, the energy reserve size of potential breeders was approximately $18 \%$ lower over the 6 -month nongrowing season (mean, $63 \mathrm{~kg}$ ) than the maximum reached over the growing season (76.3 kg; fig. $1 c$, breeders, orange line). This corresponds well to observed data, as elk in the western United States lose on average 13\% (range, 2.6\%-25\%) of their mass during winter (Cook et al. 2013). Outside the breeding month, the energy reserve component of the total phenotype of this group is maintained close to the maximum set by the fat threshold parameter ( $f=30 \%$ of total body size).

In contrast, nonbreeders carry proportionally little energy reserves throughout the year, as they allocate it 
(a) Resource and population dynamics - Whole simulation
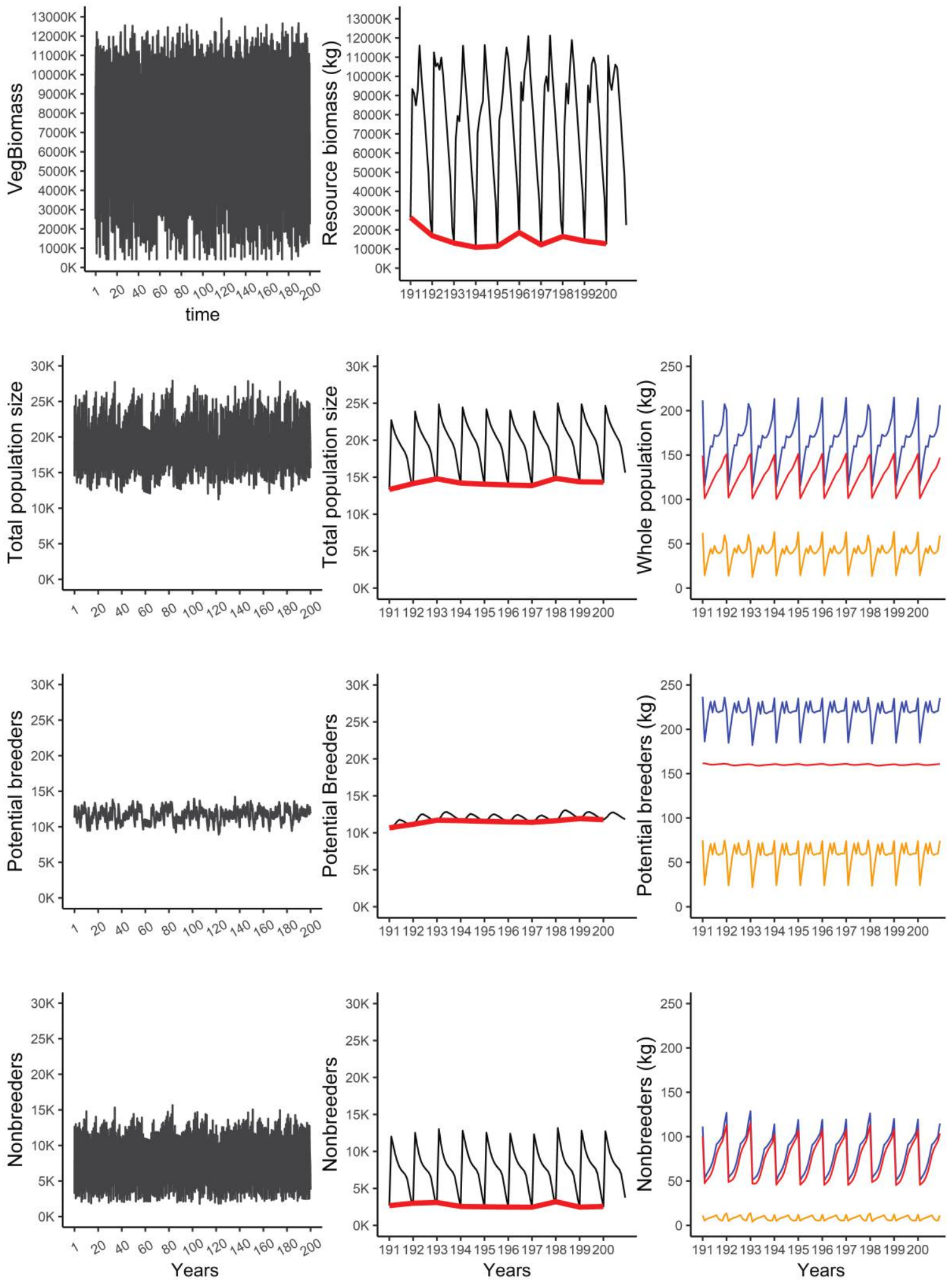

Figure 1: $a, b$, Dynamics of the elk population and resource biomass over the whole simulation (200 years; $a)$ and for the last 10 years $(b)$, with the annual prebreeding abundance superimposed (red lines). $c$, Temporal variation in mean body size in the elk population over the last 10 years of the simulation: mean total size ( $Z$, blue line), mean structural size ( $Z_{\mathrm{S}}$, red line), and mean energy reserve size $\left(Z_{\mathrm{R}}\right.$, orange line). Population dynamics and mean phenotypes are shown for the whole population and separately for potential breeders (individuals that have reached the critical size for breeding; i.e., $Z_{\mathrm{s}} \geq k$ ) and nonbreeders in the elk population. 
each month to growth (fig. $1 c$, nonbreeders, orange line). The mean structural size in this group is lowest during the breeding month (because of the influx of neonates) and increases faster during the growing season, when resources are not limiting, than during the nongrowing season (fig. $1 c$, nonbreeders, red line). The dynamics of energy reserve size in the nonbreeding group are determined both by the annual reproductive pulse and by density-dependent feedbacks operating via competition for resources over the growing and nongrowing seasons, which determine their growth dynamics.

The combined effects of these dynamic processes operating within the potential breeders and nonbreeding (growing) groups are shown for the whole population in figure 2 (where plotted values show the monthly body size distributions averaged over the 200-year simulation). The bimodal peaks in each of the mean monthly size distributions correspond to the two population groups, with shifts in the location of the distribution of structural $\left(Z_{\mathrm{S}}\right)$ and energy reserve $\left(Z_{\mathrm{R}}\right)$ phenotypes along the $X$-axis clearly depicting the growth and reproduction processes operating at different times of year (fig. 2). For example, the first peak appearing at low values of $Z_{\mathrm{S}}$ during the breeding month corresponds to the influx of neonates to the population (fig. $2 a$, red). This peak then shifts to the right (to larger $Z_{\mathrm{S}}$ values) over the year as these individuals grow in structural size (fig. $2 a$ ). The second peak in each of the mean monthly size distributions, shown in figure $2 a$, corresponds to the structural size of the potential breeders and does not change over the year. Looking at the mean monthly distribution of energy reserve size in the population (fig. $2 b$ ), the first peak at low values of $Z_{\mathrm{R}}$ during the breeding month (red) corresponds to the influx of neonates and shifts very little over the year because young individuals grow in size but do not accumulate large reserves. In contrast, the second peak, which is

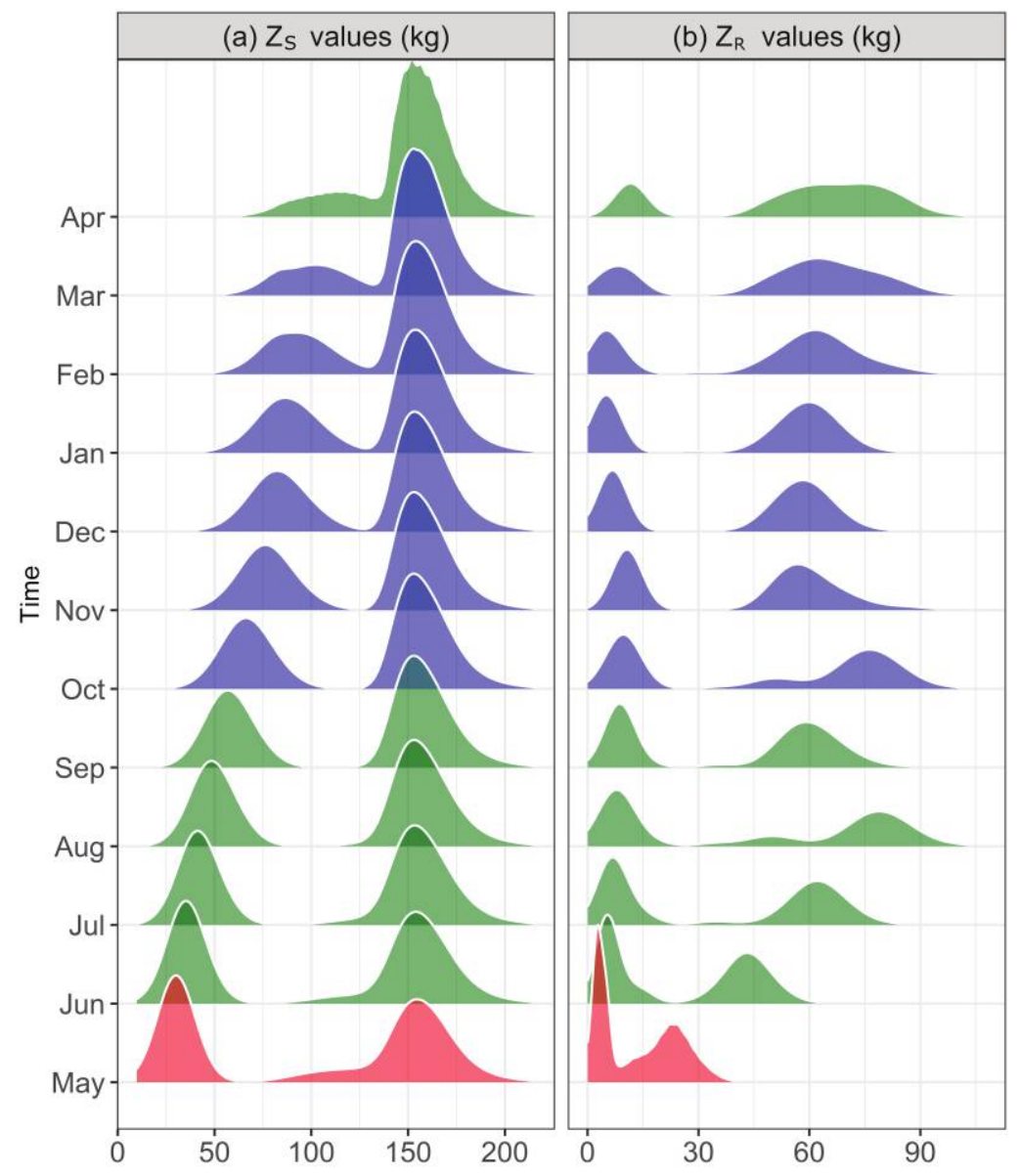

Figure 2: Distributions of mean structural size, $Z_{\mathrm{S}}(a)$, and mean energy reserve size, $Z_{\mathrm{R}}(b)$, in the simulated elk population at every month of the year (plotted monthly values are averages over the 200 -year simulation). Red $=$ breeding month; green $=$ vegetation growing months; blue $=$ vegetation nongrowing months. 
associated with the mean reserve size of potential breeders, increases rapidly in the months after breeding (during the vegetation growing season) and declines slightly over the nongrowing season (fig. $2 b$ ).

Comparing these predicted distributions of the structural size and energy reserve size with observed values for northern Yellowstone elk is not straightforward. As elk are difficult to weigh in the field, body weight is usually inferred from morphological measurements (Cook et al. 2004, 2013). Moreover, it is unclear how body weight or body condition scores correlate with the $Z_{\mathrm{R}}$ values that encompass both muscle mass and fat mass. Data on temporal changes in whole-body weights of northern Yellowstone elk suggest that our model is producing sensible results. Cook et al. (2004) reported that Yellowstone adult female elk during February and March in autumn weigh between 190 and $275 \mathrm{~kg}$, which corresponds well to the sum of $Z_{\mathrm{S}}$ and $Z_{\mathrm{R}}$ in the second "breeders" peak at this time ( 180-280 kg; fig. 2). In addition, Griffin et al. (2011) reported that the newborn calves from northern Yellowstone (age 1-10 days) weigh between 6 and $28 \mathrm{~kg}$, which corresponds closely to the sum of the $Z_{\mathrm{S}}$ and $Z_{\mathrm{R}}$ distributions corresponding to the newborn peak (the first peak) in May $(\sim 8-46 \mathrm{~kg}$; fig. 2). Furthermore, 6-8-month-old elk calves weigh on average between 80 and $100 \mathrm{~kg}$ across several northern US elk populations (Cook et al. 2013), again corresponding well to the sum of the $Z_{\mathrm{S}}$ and $Z_{\mathrm{R}}$ distributions for the "neonate" hump in November ( 60-120 kg; fig. 2).

\section{Elk Population Dynamics and Body Size Distributions under Perturbations to Bioenergetic and Demographic \\ Parameters}

Our sensitivity analyses revealed that changes $( \pm 5 \%$ or $\pm 10 \%)$ to the values of the bioenergetic parameters governing individual growth trajectories could shift the distribution of body size in the population and generate potentially large changes in population abundance and resource biomass (burn_slope, cmax_slope, fat_threshold, ZR_to_ZS; figs. $3 a-3 d, \mathrm{~S} 4)$. This suggests that body size distributions change when environmental changes act to alter the parameters governing underlying growth dynamics. Even very small changes to body size distributions could have large ramifications for population dynamics. For example, both a $10 \%$ increase in the metabolic rate coefficient (burn_slope; fig. $3 a$, yellow vs. orange-red line) and a $10 \%$ decrease in the consumption rate coefficient (cmax_slope; fig. $3 b$, dark red vs. orange-red line) decreased the mean body size in the population by a relatively small amount, yet each led to a reduction or even collapse of the population. More interestingly, the relationships between changes in body size distributions and impacts on population and resource dynamics were dis- tinctly nonlinear, with clear thresholds evident for these parameters (fig. $3 a-3 d$ ). For example, changing the proportion of energy reserves allocated to growth in growing individuals (ZR_to_ZS) altered the mean structural and energy reserve size of individuals but only resulted in population impacts (population collapse) at values above 50\% (ZR_to_ZS; fig. $3 d$ ). At high values of ZR_to_ZS, growth in structural size occurs rapidly and at the expense of reserve accumulation, such that nonbreeding individuals are larger but in poorer condition and thus more likely to die of starvation over the winter nongrowing period.

The nonlinearity in associations between body size distributions and population dynamics was further evident in how changes to parameter values that decreased mean body size (particularly a decrease in mean $Z_{\mathrm{R}}$ ) had larger impacts on population dynamics than those that increased mean body size. There are two explanations for this. As elk are a long-lived species, survival rates are high and increase rapidly with size. Hence, the shape of the survival function for this species implies that reductions in mean body size will have far greater consequences for average survival rates than will comparable increases in mean body size (see, e.g., fig. S5). Second, when populations are at carrying capacity (as was the case for our baseline population), then any change to parameter values that increases survivorship of individuals should be offset by decreased reproductive output because of an increase in the strength of densitydependent processes. This is indeed what we found. Reproductive output (the mean proportion breeding and the proportion of years with $100 \%$ reproduction) declined linearly with parameter changes that favored increased individual survivorship via an increase in mean body size (i.e., decreasing metabolic rate, increasing consumption rate, increasing fat threshold, and decreasing allocation of energy reserves to growth; fig. 3a-3d; table S1, pts. a-d; tables S1, S2 are available online).

In contrast, small changes in demographic parameters (neonate_mortality, surv_slope [the slope of the survival function], ZR_to_reproZ [the amount of energy reserve mass allocated to reproduction], and reproZ_to_offspringZS [the amount allocated to structural size in offspring]) had minimal effects on body size distributions, population abundance, and resource biomass (fig. $3 f-3 i$ ). Changes to these four parameters did not alter the growth dynamics of individuals but instead directly on demographic rates. However, these changes were of insufficient magnitude to impact population dynamics and were offset by a densitydependent reduction in reproductive output, as discussed above (table S1). The exception to this pattern was changes to the value of the intercept of the survival function (fig. $3 e$, surv_int). Decreasing the survival prospects of individuals in the population resulted in lower population abundance, with population collapse occurring at the lowest 


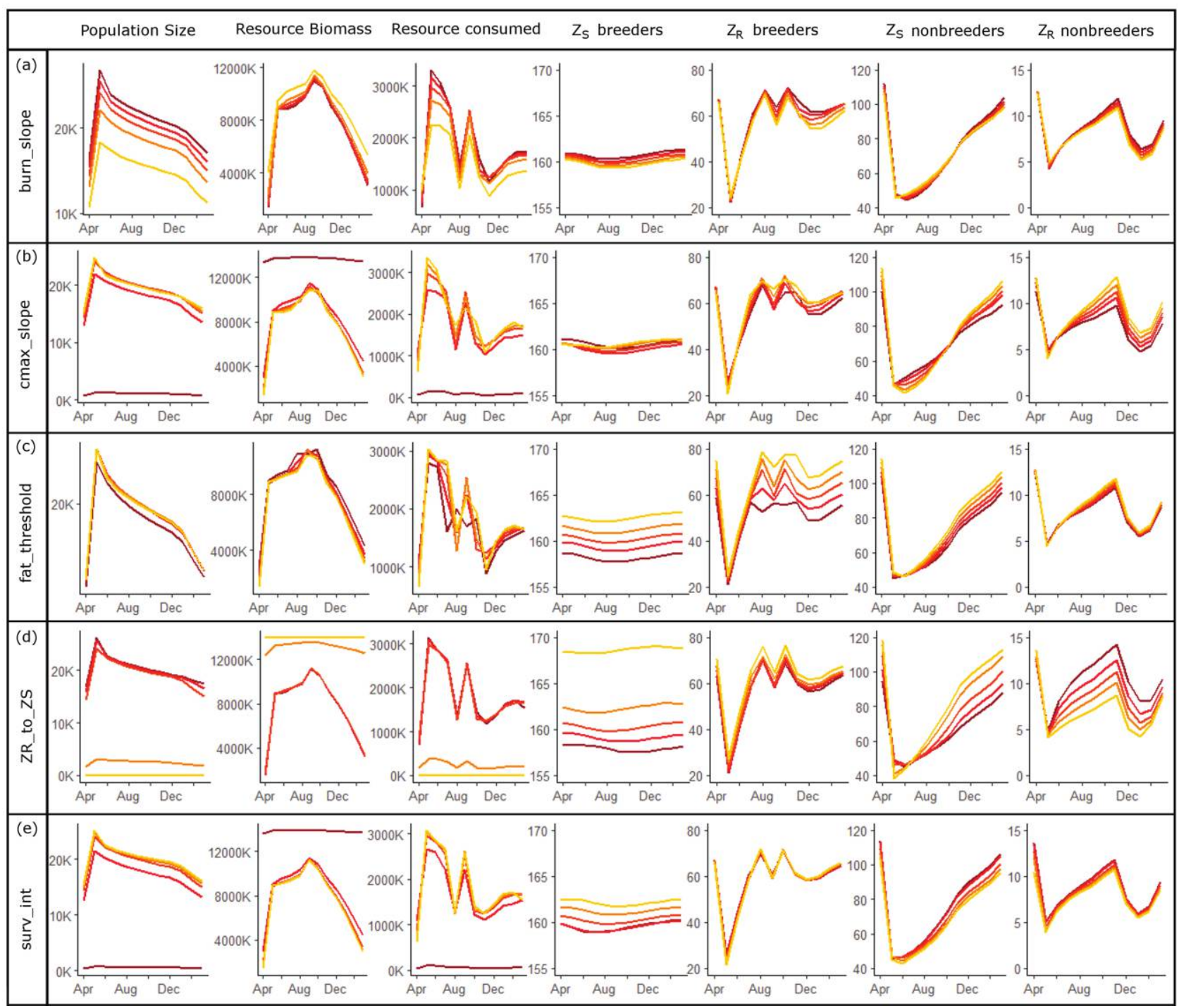

Figure 3: Results of sensitivity analysis investigating elk-resource dynamics under perturbations of bioenergetic and demographic parameters (see table 2 for details of parameters varied). Graphs show monthly means for population size, resource biomass (kg), amount of resource consumed $(\mathrm{kg})$, and structural $\left(Z_{\mathrm{S}}\right)$ and energy reserve $\left(Z_{\mathrm{R}}\right)$ body size $(\mathrm{kg})$ of potential breeders and nonbreeders for each month of the 200-year simulation. The color gradient of plotted lines corresponds to the parameter range tested (darkest = lowest values; lightest $=$ highest values; see table 2).

value tested (fig. $3 e$ ). That changing survival rates had a greater impact than did changing other demographic parameters is unsurprising given the importance of survival to the population dynamics of long-lived species such as elk (Gaillard et al. 1998; Sæther and Bakke 2000). Yet increasing the value of the survival intercept did not result in a greater population abundance (fig. 3e). Again, this was likely due to an increase in the strength of densitydependent feedback operating to regulate the population at carrying capacity via a reduction in reproductive output (the mean proportion breeding and the proportion of years with $100 \%$ breeding were lower at higher values of survival intercept; table S1).

\section{Elk Population Dynamics and Body Size Distributions under Changing Patterns of Seasonality}

We found that increasing the duration of the vegetation growing season and reducing the productivity of the growing season had far greater impacts on the population dynamics of elk than did reducing the severity of winter 


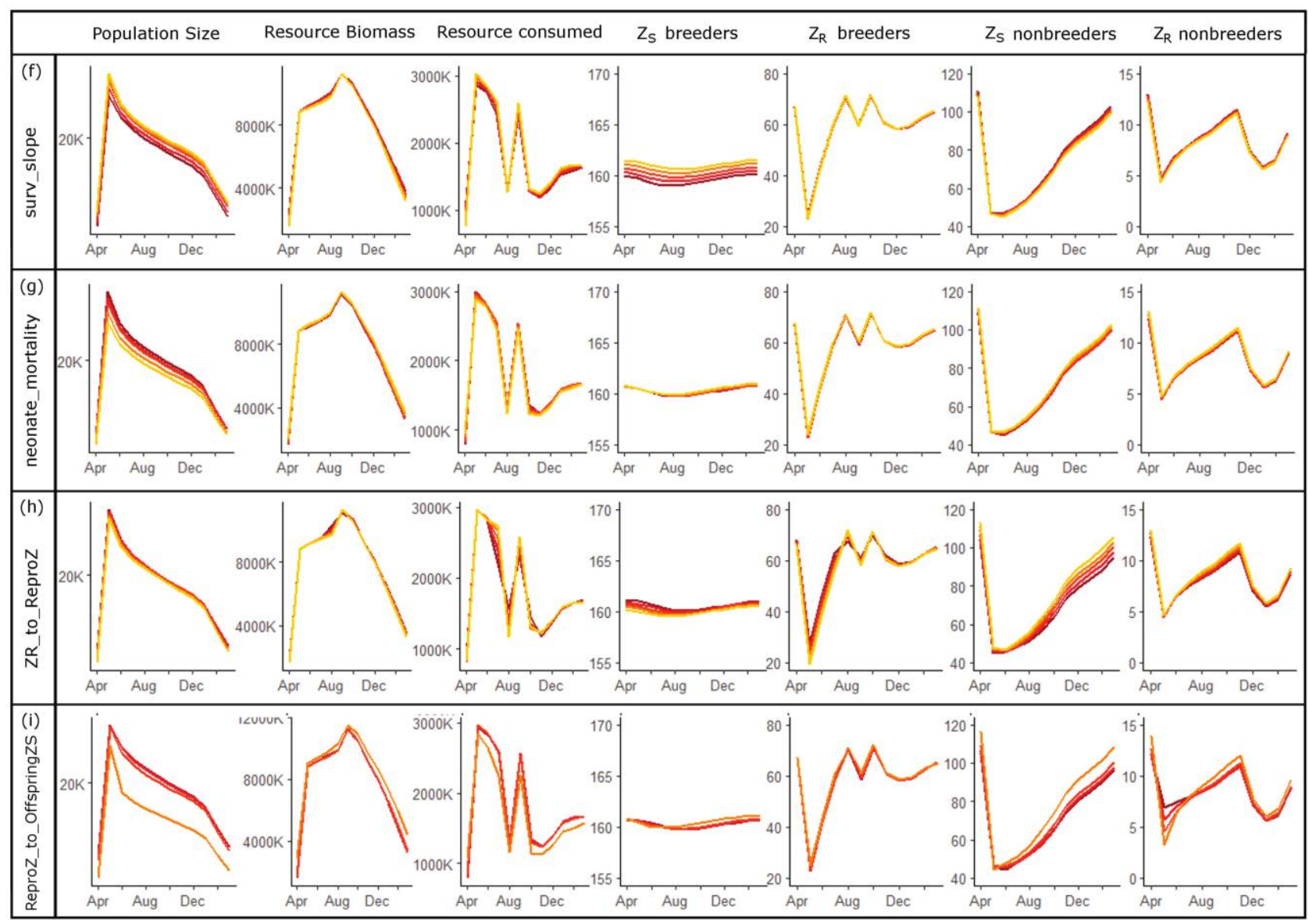

Figure 3 (Continued)

(fig. $4 a, 4 b$ vs. fig. $4 c, 4 d$ ). In response to a longer vegetation growing season, the simulated elk population increased markedly in abundance and consumed a greater amount of vegetation throughout the year (fig. $4 a$ ). In response to reduced resource productivity during the growing season, the opposite occurred: the population decreased in abundance and consumed less vegetation (fig. $4 b$ ). Interestingly, our model output showed that these population-level changes occurred in the absence of phenotypic changes to the distribution of body size in the population. Neither the mean structural size nor the mean energy reserve size of individuals differed between these two seasonal simulations and the baseline model (fig. $4 a, 4 b$ ). In addition, reproductive output varied relatively little between the baseline model and these two seasonal variants (the apparent greater variability of reproduction under the "lower-productivity" season was driven by just 4 years in which reproduction was low; $<60 \%$; table S2). Thus, we can conclude that the population impacts of a longer or less productive growing season transpired primarily because these environmental changes increased or decreased resource availability, which directly affected individual survival rates as a result of reduced or strengthened density-dependent competition for resources.

In contrast, reducing the duration or extent of snowfall during the nongrowing season had comparatively little impact on elk population size or the biomass of vegetation present (fig. $4 c, 4 d$ ). Nevertheless, changing these two environmental processes did alter the body size composition of the population. Under less severe winter conditions individuals consumed more resources during the nongrowing period (fig. $4 c, 4 d$ ). Individuals were thus fatter over the winter nongrowing period (a larger $Z_{\mathrm{R}}$ for both potential breeders and nonbreeders) although slightly smaller overall (smaller $Z_{\mathrm{s}}$; fig. $4 c, 4 d$ ). This pattern occurred because individuals that are in better condition over the winter (i.e., have greater energy reserves) can mature at slightly smaller sizes (if, e.g., they do not require an additional year of growth to reach breeding size). Consequently, they produce slightly 


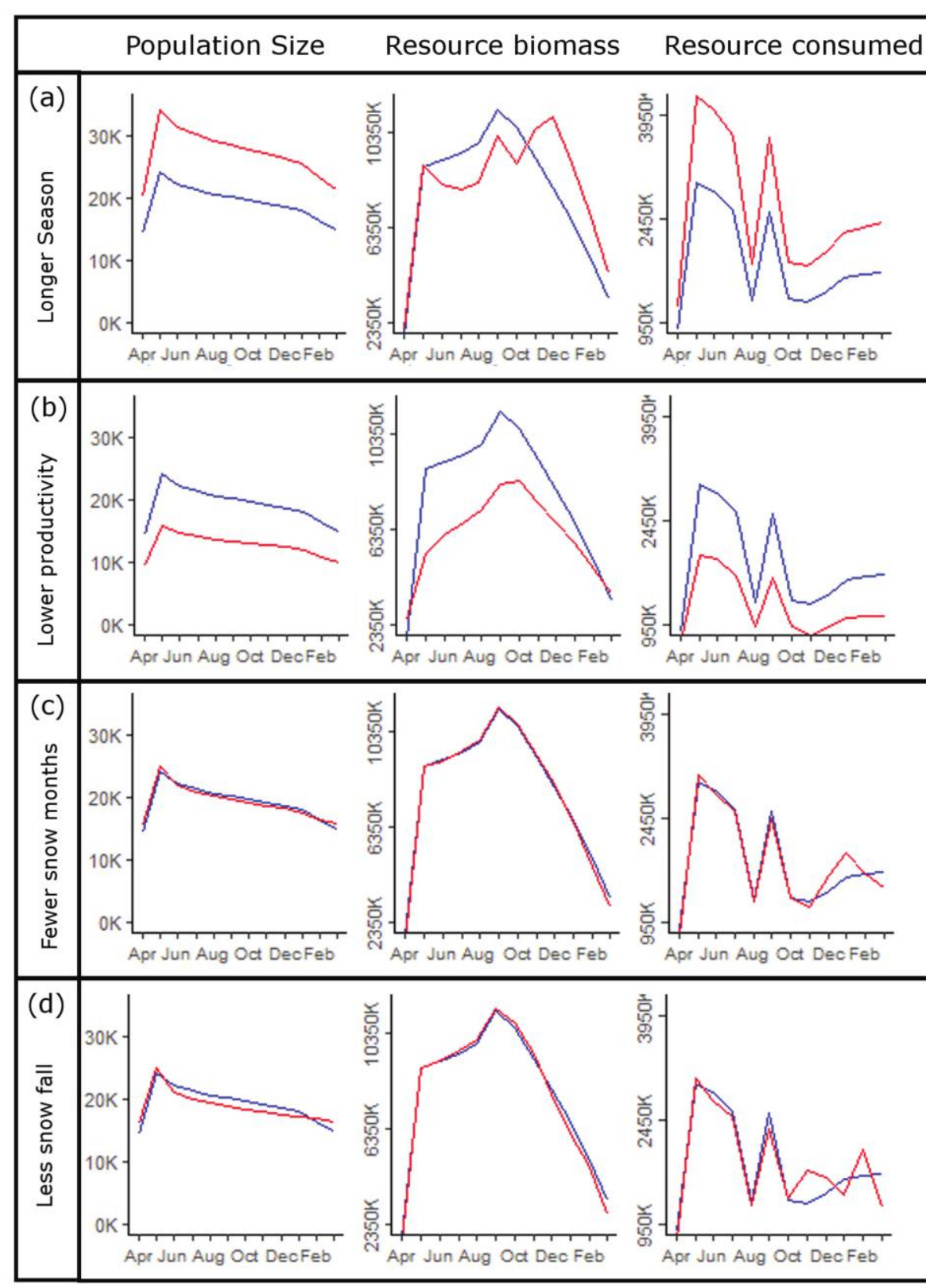

Figure 4: Results of seasonality analysis investigating elk-resource dynamics under different patterns of seasonality (see table 3 for details of simulated seasons). Graphs show the mean population size, resource biomass, amount of resource consumed, and structural $\left(Z_{\mathrm{s}}\right)$ and energy reserve $\left(Z_{\mathrm{R}}\right)$ body size of breeders and nonbreeders in each month of the 200-year simulation. In each graph, results for the baseline model are shown in blue, while results for the seasonal variant are shown in red.

smaller offspring (as they have proportionally less energy reserve mass to allocate to reproduction than do larger individuals), which nonetheless grow more rapidly than under baseline conditions, as they also have access to greater energy reserves over the milder winter (fig. $4 c, 4 d$ ). Improved body condition over the winter should increase survival and re- production rates, potentially altering population abundance. This did not transpire in our simulation, either because these changes were of insufficient magnitude or because they were counteracted by density-dependent processes (or both). As changes to snowfall duration and extent during the nongrowing season did not markedly increase or decrease 


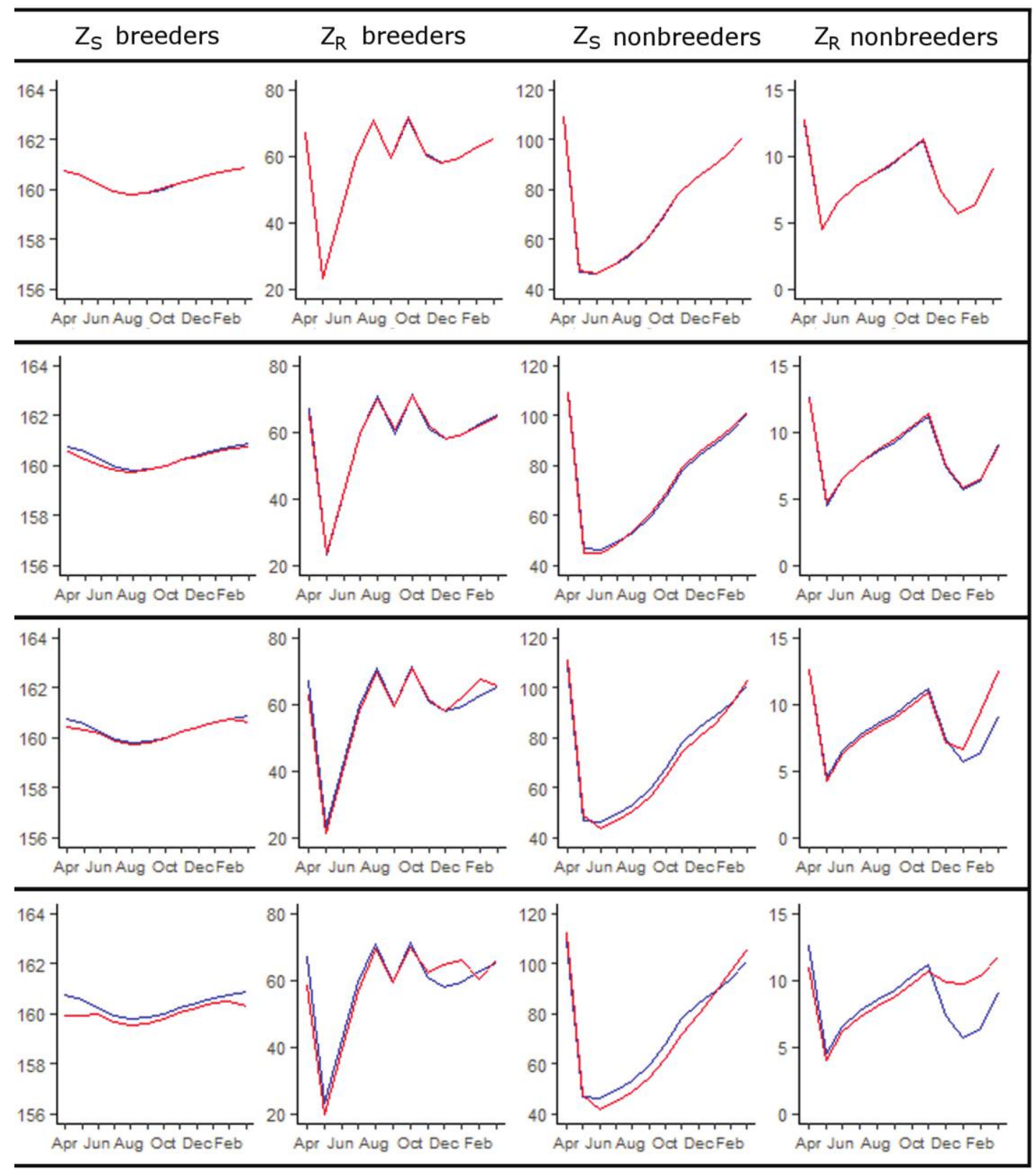

Figure 4: (Continued)

resource availability across the year, the carrying capacity of the system remained unchanged relative to the baseline. Consequently, the potential increases in survival rates that would have been mediated by observed increases to mean winter energy reserve mass under these two seasonal variants were offset by density-dependent reductions in reproductive output relative to the baseline model (table S2).
Discussion

Our work provides several insights into how environmental change affects population dynamics via associations between phenotypes, demography, and resource availability. First, we have shown that when environmental change alters demographic rates directly, population change can 
ensue in the absence of substantial changes to population composition, such that populations will be composed of fewer or more individuals that occupy the same phenotypic distribution. We found that directly altering the demographic rates of individuals in our simulated population had little impact on mean body size in the population because the environmental change benefited or burdened all individuals to the same extent and because the underlying individual growth dynamics were unaffected (i.e., the rate at which individuals consumed and metabolized resources remained unchanged). In our study, this occurred when the environmental change greatly altered the availability of resources, as this modified the strength of intraspecific competition for resources and consequently the strength of density-dependent feedback processes operating on demographic rates.

In addition, we observed that under some circumstances environmental change can alter body size distributions with little consequence for population dynamics, such that populations will be composed of a similar number of differentsized individuals. In our study, this occurred when the effect of the environmental change on resource availability was small and restricted to the nongrowing season. Previous work has shown that when body size has a small effect on vital rates, changes in body size will not propagate to alter population dynamics, even though they may influence other life-history processes (Pelletier et al. 2007; van Benthem et al. 2017). This reveals that fluctuations in population abundance and body size can result from different life-history processes and that environmental processes must affect body size-vital rate combinations that have high elasticity to impact population growth (Ozgul et al. 2012; Tredennick et al. 2018). However, neither of these considerations adequately explains our result. Our sensitivity analyses demonstrated that body size was strongly linked to demographic rates and population dynamics but in a nonlinear manner, such that decreases in mean body size led to larger population effects than did increases in mean body size. This finding adds to previous work demonstrating the importance of nonlinear effects of size asymmetries on population dynamics, persistence, and cycling (De Roos et al. 2003). We also found that strong density-dependent processes operating to regulate our simulated population at carrying capacity could offset trait-mediated increases in vital rates and therefore counteract expected population responses to environmental change. Our work highlights that the direction and magnitude of environmentally driven shifts in body size distribution and ecological carrying capacity are both important in determining the nature of population responses to environmental change. Accordingly, we suggest that a more complete understanding of how associations between body size and demography influence population responses to environmental change will require consideration of the shape of the relationships between phenotypic distributions and vital rates, the population status with regard to its ecological carrying capacity, and importantly the direction and magnitude of the environmentally driven change in both phenotypes and ecological carrying capacity.

Although environmentally driven shifts in the body size distribution of elk in this study did not in themselves translate to changes at the population level, they are nonetheless likely to have important consequences for population dynamics when considered in the context of more complex community interactions. In multitrophic systems, changes in body size distributions can influence both population dynamics and ecological structure by modifying the outcomes of interspecific interactions (De Roos et al. 2003; Griffiths et al. 2018; Detmer and Wahl 2019). For example, shifts in the body size distribution of one species can alter the balance of asymmetric competition between sympatric species competing for limited resources (De Roos et al. 2003; Eccard and Ylönen 2003; Bassar et al. 2017; Brose et al. 2017). Similarly, selective predation can create asymmetries in mortality rates between small and large individuals or individuals in poor or good condition, which can influence population dynamics or the strength of trophic cascades (Day et al. 2002; Hülsmann et al. 2011; Detmer and Wahl 2019). The results of our seasonal simulations confirmed that milder winters enabled elk to be in better condition over winter (i.e., greater mean energy reserve mass for structural size). In the context of our two-level consumerresource model, this shift in phenotypic body size distribution did not translate to changes in population dynamics (for reasons discussed above). However, northern Yellowstone elk may compete with bison for resources and suffer size- and condition-dependent predation (with smaller and weaker individuals being most susceptible; Metz et al. 2012). When seen within this community context, a potential shift in the body condition of elk over winter could have significant ramifications for elk population dynamics and community structure. We are currently working to extend our modeling framework to incorporate multitrophic interactions in order to better understand the role that environmentally driven shifts in the body size distribution of elk play in mediating the outcome of intra- and interspecific interactions in this system.

Environmental change is an inherently multivariate phenomenon. Identifying exactly which weather covariates and processes impact individual performance and demographic rates is a difficult problem (Smith-Ramesh et al. 2018). Our work reveals just how complex changing climatic processes can be for herbivores via their indirect effects on resource availability. Climate change forecasts for patterns of seasonality in temperate environments predict milder winters and hotter and drier summers, leading to an increase in the duration of the vegetation growing season and a concomitant 
decline in resource productivity (IPCC 2013; Chang and Hansen 2014). The results of our model simulations revealed that these varied climatic processes led to profoundly different and conflicting effects on our simulated elk population. In particular, we found that the detrimental effects of a reduction in resource productivity on population size were of a magnitude similar to that of the beneficial effect of a longer vegetation growing season, offering a potential means of compensation.

The bioenergetic IPM we built captured the key population characteristics of northern Yellowstone elk for which it was parameterized (in the absence of predation). It predicts realistic temporal patterns of body size changes for this species and credible population responses to simulated changes in patterns of seasonality. Studies have shown that the dynamics of long-lived species such as elk are most susceptible to variations in survival of prime-age individuals (Gaillard et al. 1998; Sæther and Bakke 2000). In addition, ungulate populations are known to be strongly regulated through density-dependent mortality and reproduction, with environmental variation combining with density dependence through a common effect on resource supply (Illius and O'Connor 2000). Thus, it is perhaps not surprising that we found that the population dynamics of our simulated elk population were more strongly affected by environmental changes that directly influenced survival rates and modified the strength of density-dependent processes than by processes that modified the distribution of body sizes in the population. Our inferences in this study are particular to the system we chose to model. Nevertheless, in light of the results of our model and our understanding of model behavior, we would expect that for organisms with different life-history patterns and where body size exerts very large effects on survival or reproduction (e.g., many fish and invertebrate species), plastic variation in growth or strong environmental impacts on growth could have far more substantial effects on population dynamics than those observed in our system. The model we have developed here can be readily transported to other herbivore systems where growth is dependent on a dynamic resource base, including St. Kilda sheep (Coulson et al. 2001), Serengeti wildebeest (Mduma et al. 1999), and grazing reef fish (Williams and Polunin 2001), if the baseline data are available. Moreover, extension of this model to include competition between sympatric species (e.g., elk and bison) could also provide for more nuanced understanding of population dynamics in seasonally varying environments, and it is the focus of our ongoing work.

Ecological modeling requires making a trade-off between biological realism (complexity) and tractability. A functional model must strike a balance by incorporating sufficient detail to capture the necessary ecological processes while remaining simple enough to help understand the dynamics of those processes (Trebitz et al. 2000). To facilitate the tractability and generality of our model, we assumed that individual energy budgets were determined only by fluctuations in resource availability in the environment and the physiological state of an individual (its structural and energy reserve size and its potential to breed). Metabolic costs for large herbivores in temperate environments will vary seasonally as a result of a combination of multiple processes (Lovegrove 2005). Thermoregulatory costs can increase with exposure to harsh weather conditions (temperature extremes, increased precipitation, wind speeds, or solar radiation) and are typically elevated in both summer and winter, although they exhibit great variation even within seasons (Parker and Robbins 1984; Lovegrove 2005; Glushkov and Kuznetsov 2015). Additionally, locomotor costs can increase during winter because of the additional energy expenditure required to move through snow, although the extent to which this occurs depends strongly on the duration, depth, and density of winter snowfall (Parker et al. 1984; DelGiudice et al. 1991). To further complicate matters, both thermoregulatory and locomotor costs can be moderated by aspects of individual behavior (e.g., altered movement patterns; Long et al. 2014; Glushkov and Kuznetsov 2015). Because of these numerous complexities, we chose to not explicitly link individual energy budgets to environmental conditions or to include locomotor costs, instead subsuming these energetic expenditures within our general metabolic costs. The model framework we developed can be extended to accommodate more complex environmentally linked energy budgets. While this was beyond the scope of this project, we anticipate that such an undertaking will provide a more nuanced understanding of the mechanisms linking demographic responses to environmental change in this population.

To further facilitate the computational tractability of our model, we modeled only the female part of the population and incorporated all reproductive costs into one time period (at the start of the growing season). Males are often neglected in studies of ungulate population dynamics because male availability does not limit female reproduction. Females generally produce and raise young on their own, and there is often little overlap in habitat use between the sexes (Gaillard et al. 1998). Hence, modeling the dynamics of the female component of the population may suffice to adequately describe the population dynamics of many ungulate species. Nevertheless, there is increasing recognition that the presence and behavior of males matter to population processes (Mysterud et al. 2002; Rankin and Kokko 2007). Particularly relevant to our bioenergetic IPM is the fact that the dynamics of energy acquisition and allocation may differ temporally between females and males (Parker et al. 2009). In ungulate species living in temperate environments, the peak energetic demands for females occur over spring and early summer (when gestation/lactation costs are high), 
but for males these occur during the autumn rut (White et al. 2008; Parker et al. 2009; Douhard et al. 2018). Hence, males often start winter in poorer condition, having reduced their body reserves during the rut (Cook et al. 2016). These divergent patterns could alter the strength of competition for limiting resource between males and females, with potential ramifications both for the strength of density-dependent processes and for the dynamics of body size changes in males and females. Similarly, our compression of reproductive costs into a single time period ignored the potential for temporal variation in the metabolic costs of offspring production (gestation and birth) versus provisioning (lactation) to interact with changing resource availability and influence competitive interactions, phenotypic changes, and population processes. The IPM framework we employed in this article can be readily generalized to include age and sex structure (Ellner and Rees 2006), genetic variation (Coulson et al. 2011), asymmetric competition (Bassar et al. 2016), and different, nonrandom mating systems (Schindler et al. 2013). Extension of our model to include two sexes and a more realistic temporal portrayal of reproduction costs is the focus of our ongoing work.

Despite increasing interest in elucidating associations between phenotypic and demographic responses to environmental change, we still lack an understanding of the conditions under which these processes are linked and how these links arise. Using a mechanistic population model that jointly models population and resource dynamics alongside the dynamics of demography and body size distributions, we show that small changes in phenotypic trait distributions can generate large changes in population dynamics but that these need not trigger population responses to environmental change. We further show that population responses to environmental change will be a product of the degree to which different environmental processes affect resource availability throughout the year, the strength and shape of the association between body size and vital rate functions (which is likely to be highly nonlinear), where the population lies with respect to the ecological carrying capacity, and subsequently the strength of density-dependent feedback processes.

\section{Acknowledgments}

S.L. acknowledges the Daphne Jackson Trust, the Natural Environment Research Council, and Wolfson College. T.C. acknowledges the European Research Council and the Natural Environment Research Council. P.J.H. acknowledges the Willaman Chair from Penn State College of Science. M.E.C. was funded by the National Science Foundation. We thank many donors to Yellowstone Forever, especially Annie and Bob Graham and Valerie Gates. We also thank Campbell Allen for help with model coding and computing. We acknowledge the anonymous reviewers for valuable comments on an early version of the manuscript.

\section{Statement of Authorship}

S.L. and T.C. developed the question and research approach. S.L. and T.C. developed the model structure and wrote the scripts (in R) to run simulations, conduct analyses, and visualize model output. S.L. wrote the manuscript with input from all coauthors. All coauthors edited and provided significant comments on multiple manuscript drafts.

\section{Literature Cited}

Bassar, R. D., D. Z. Childs, M. Rees, S. Tuljapurkar, D. N. Reznick, and T. Coulson. 2016. The effects of asymmetric competition on the life history of Trinidadian guppies. Ecology Letters 19:268-278.

Bassar, R. D., J. Travis, and T. Coulson. 2017. Predicting coexistence in species with continuous ontogenetic niche shifts and competitive asymmetry. Ecology 98:2823-2836.

Benton, T. G., S. J. Plaistow, and T. N. Coulson. 2006. Complex population dynamics and complex causation: devils, details and demography. Proceedings of the Roval Society B 273:1173-1181.

Bolnick, D. I., P. Amarasekare, M. S. Araujo, R. Burger, J. M. Levine, M. Novak, V. H. W. Rudolf, et al. 2011. Why intraspecific trait variation matters in community ecology. Trends in Ecology and Evolution 26:183-192.

Bradshaw, W. E., and C. M. Holzapfel. 2006. Evolutionary response to rapid climate change. Science 312:1477-1478.

Brose, U., J. L. Blanchard, A. Eklof, N. Galiana, M. Hartvig, M. R. Hirt, G. Kalinkat, et al. 2017. Predicting the consequences of species loss using size-structured biodiversity approaches. Biological Reviews 92:684-697.

Chang, T., and A. J. Hansen. 2014. Climate change brief: Greater Yellowstone ecosystem, landscape climate change vulnerability project. Montana State University, Bozeman.

Christianson, D. A., and S. Creel. 2007. A review of environmental factors affecting elk winter diets. Journal of Wildlife Management 71:164-176.

- 2009. Effects of grass and browse consumption on the winter mass dynamics of elk. Oecologia 158:603-613.

Colchero, F., O. R. Jones, D. A. Conde, D. Hodgson, F. Zajitschek, B. R. Schmidt, A. F. Malo, et al. 2019. The diversity of population responses to environmental change. Ecology Letters 22:342-353.

Cook, J. G., R. C. Cook, R. W. Davis, and L. L. Irwin. 2016. Nutritional ecology of elk during summer and autumn in the Pacific Northwest. Wildlife Monographs 195:1-81.

Cook, R. C., J. G. Cook, and L. D. Mech. 2004. Nutritional condition of northern Yellowstone elk. Journal of Mammalogy 85:714-722.

Cook, R. C., J. G. Cook, D. J. Vales, B. K. Johnson, S. M. McCorquodale, L. A. Shipley, R. A. Riggs, et al. 2013. Regional and seasonal patterns of nutritional condition and reproduction in elk. Wildlife Monographs 184:46.

Coulson, T. 2012. Integral projections models, their construction and use in posing hypotheses in ecology. Oikos 121:1337-1350.

Coulson, T., E. A. Catchpole, S. D. Albon, B. J. Morgan, J. M. Pemberton, T. H. Clutton-Brock, M. J. Crawley, et al. 2001. Age, 
sex, density, winter weather, and population crashes in Soay sheep. Science 292:1528-1531.

Coulson, T., D. R. MacNulty, D. R. Stahler, B. vonHoldt, R. K. Wayne, and D. W. Smith. 2011. Modeling effects of environmental change on wolf population dynamics, trait evolution, and life history. Science 334:1275-1278.

Day, T., P. A. Abrams, and J. M. Chase. 2002. The role of size-specific predation in the evolution and diversification of prey life histories. Evolution 56:877-887.

DelGiudice, G. D., F. J. Singer, and U. S. Seal. 1991. Physiological assessment of winter nutritional deprivation in elk of Yellowstone National Park. Journal of Wildlife Management 55:653-664.

De Roos, A. M., N. Galic, and H. Heesterbeek. 2009. How resource competition shapes individual life history for nonplastic growth: ungulates in seasonal food environments. Ecology 90:945-960.

De Roos, A. M., L. Persson, and E. McCauley. 2003. The influence of size-dependent life-history traits on the structure and dynamics of populations and communities. Ecology Letters 6:473-487.

Detmer, T. M., and D. H. J. A. S. Wahl. 2019. Trophic cascade strength is influenced by size frequency distribution of primary consumers and size-selective predation: examined with mesocosms and modeling. Aquatic Sciences 81:52.

Douhard, M., S. Guillemette, M. Festa-Bianchet, and F. Pelletier. 2018. Drivers and demographic consequences of seasonal mass changes in an alpine ungulate. Ecology 99:724-734.

Dubos, N., I. Le Viol, A. Robert, C. Teplitsky, M. Ghislain, O. Dehorter, R. Julliard, et al. 2018. Disentangling the effects of spring anomalies in climate and net primary production on body size of temperate songbirds. Ecography 41:1319-1330.

Eberhardt, L. L., P. J. White, R. A. Garrott, and D. B. Houston. 2007. A seventy-year history of trends in Yellowstone's northern elk herd. Journal of Wildlife Management 71:594-602.

Eccard, J. A., and H. J. E. E. Ylönen. 2003. Interspecific competition in small rodents: from populations to individuals. Evolutionary Ecology 17:423-440.

Ellner, S. P., and M. Rees. 2006. Integral projection models for species with complex demography. American Naturalist 167:410-428.

Field, R. A., F. C. Smith, W. G. Hepworth, and W. J. Means. 2003. The elk carcass. College of Agriculture, University of Wyoming.

Foley, A. M., P. C. Cross, D. A. Christianson, B. M. Scurlock, and S. Creel. 2015. Influences of supplemental feeding on winter elk calf: cow ratios in the southern Greater Yellowstone Ecosystem. Journal of Wildlife Management 79:887-897.

Fortin, D., J. M. Morales, and M. S. Boyce. 2005. Elk winter foraging at fine scale in Yellowstone National Park. Oecologia 145:334-342.

Frank, D. A., R. L. Wallen, and P. J. White. 2016. Ungulate control of grassland production: grazing intensity and ungulate species composition in Yellowstone Park. Ecosphere 7:e01603.

Gaillard, J. M., M. Festa-Bianchet, and N. G. Yoccoz. 1998. Population dynamics of large herbivores: variable recruitment with constant adult survival. Trends in Ecology and Evolution 13:58-63.

Gaillard, J. M., A. J. M. Hewison, F. Klein, F. Plard, M. Douhard, R. Davison, and C. Bonenfant. 2013. How does climate change influence demographic processes of widespread species? lessons from the comparative analysis of contrasted populations of roe deer. Ecology Letters 16:48-57.

Garroutte, E. L., A. J. Hansen, and R. L. Lawrence. 2016. Using NDVI and EVI to map spatiotemporal variation in the biomass and quality of forage for migratory elk in the Greater Yellowstone ecosystem. Remote Sensing 8:25.
Glushkov, V. M., and G. V. Kuznetsov. 2015. Morphophysiological and behavioral adaptations of elk to wintering. Biology Bulletin 42:371-377.

Griffin, K. A., M. Hebblewhite, H. S. Robinson, P. Zager, S. M. Barber-Meyer, D. Christianson, S. Creel, et al. 2011. Neonatal mortality of elk driven by climate, predator phenology and predator community composition. Journal of Animal Ecology 80:1246-1257.

Griffiths, J. I., O. L. Petchey, F. Pennekamp, and D. Z. Childs. 2018. Linking intraspecific trait variation to community abundance dynamics improves ecological predictability by revealing a growth-defense trade-off. Functional Ecology 32:496-508.

Hempson, G. P., A. W. Illius, H. H. Hendricks, W. J. Bond, and S. Vetter. 2015. Herbivore population regulation and resource heterogeneity in a stochastic environment. Ecology 96:2170-2180.

Houston, D. B. 1982. The northern Yellowstone elk: ecology and management. MacMillan, New York.

Hoy, S. R., R. O. Peterson, and J. A. Vucetich. 2018. Climate warming is associated with smaller body size and shorter lifespans in moose near their southern range limit. Global Change Biology 24:2488-2497.

Hülsmann, S., K. Rinke, and W. M. Mooij. 2011. Size-selective predation and predator-induced life-history shifts alter the outcome of competition between planktonic grazers. Functional Ecology 25:199-208.

Illius, A. W., and T. G. O'Connor. 2000. Resource heterogeneity and ungulate population dynamics. Oikos 89:283-294.

IPCC (Intergovernmental Panel on Climate Change). 2013. Climate change 2013: the physical science basis. Contribution of Working Group I to the Fifth Assessment Report of the Intergovernmental Panel on Climate Change. T. F. Stocker, D. Qin G. K. Plattner, M. Tignor, S. K. Allen, J. Boschung, A. Nauels, et al., eds. Cambridge University Press, Cambridge.

Isaac, J. L. 2009. Effects of climate change on life history: implications for extinction risk in mammals. Endangered Species Research 7:115-123.

Jiang, Z., and R. J. Hudson. 1992. Estimating forage intake and energy requirements of free-ranging wapiti (Cervus elaphus). Canadian Journal of Zoology 70:675-679.

Kauffman, M. J., J. F. Brodie, and E. S. Jules. 2010. Are wolves saving Yellowstone's aspen? a landscape-level test of a behaviorally mediated trophic cascade. Ecology 91:2742-2755.

Lawson, C. R., Y. Vindenes, L. Bailey, and M. van de Pol. 2015. Environmental variation and population responses to global change. Ecology Letters 18:724-736.

Lika, K., and R. M. Nisbet. 2000. A dynamic energy budget model based on partitioning of net production. Iournal of Mathematical Biology 41:361-386.

Long, R. A., R. T. Bowyer, W. P. Porter, P. Mathewson, K. L. Monteith, and J. G. Kie. 2014. Behavior and nutritional condition buffer a large-bodied endotherm against direct and indirect effects of climate. Ecological Monographs 84:513-532.

Lovegrove, B. G. 2005. Seasonal thermoregulatory responses in mammals. Journal of Comparative Physiology B 175:231-247.

MacNulty, D. R., D. R. Stahler, C. T. Wyman, J. Ruprecht, and D. W. Smith. 2016. The challenge of understanding northern Yellowstone elk dynamics after wolf reintroduction. Yellowstone Science 24:25-33.

Mason, T. H., M. Apollonio, R. Chirichella, S. G. Willis, and P. A. Stephens. 2014. Environmental change and long-term body mass declines in an alpine mammal. Frontiers in Zoology 11:69. 
Mduma, S. A. R., A. R. E. Sinclair, and R. Hilborn. 1999. Food regulates the Serengeti wildebeest: a 40-year record. Iournal of Animal Ecology 68:1101-1122.

Merow, C., J. P. Dahlgren, C. J. E. Metcalf, D. Z. Childs, M. E. K. Evans, E. Jongejans, S. Record, et al. 2014. Advancing population ecology with integral projection models: a practical guide. Methods in Ecology and Evolution 5:99-110.

Metz, M. C., D. W. Smith, J. A. Vucetich, D. R. Stahler, and R. O. Peterson. 2012. Seasonal patterns of predation for gray wolves in the multi-prey system of Yellowstone National Park. Lournal of Animal Ecology 81:553-563.

Mysterud, A., T. Coulson, and N. C. Stenseth. 2002. The role of males in the dynamics of ungulate populations. Journal of Animal Ecology 71:907-915.

Nelson, W. A., B. Joncour, D. Pak, and O. N. Bjornstad. 2019. Asymmetric interactions and their consequences for vital rates and dynamics: the smaller tea tortrix as a model system. Ecology 100:e02558.

Owen-Smith, N. 2002. A metaphysiological modelling approach to stability in herbivore-vegetation systems. Ecological Modelling 149:153-178.

Ozgul, A., D. Z. Childs, M. K. Oli, K. B. Armitage, D. T. Blumstein, L. E. Olson, S. Tuljapurkar, et al. 2010. Coupled dynamics of body mass and population growth in response to environmental change. Nature 466:482-485.

Ozgul, A., T. Coulson, A. Reynolds, T. C. Cameron, and T. G. Benton. 2012. Population responses to perturbations: the importance of trait-based analysis illustrated through a microcosm experiment. American Naturalist 179:582-594.

Parker, K. L., P. S. Barboza, and M. P. Gillingham. 2009. Nutrition integrates environmental responses of ungulates. Functional Ecology 23:57-69.

Parker, K. L., and C. T. Robbins. 1984. Thermoregulation in mule deer and elk. Canadian Journal of Zoology 62:1409-1422.

Parker, K. L., C. T. Robbins, and T. A. Hanley. 1984. Energy expenditures for locomotion by mule deer and elk. Journal of Wildlife Management 48:474-488.

Pearce-Higgins, J. W., N. Ockendon, D. J. Baker, J. Carr, E. C. White, R. E. A. Almond, T. Amano, et al. 2015. Geographical variation in species' population responses to changes in temperature and precipitation. Proceedings of the Roval Society B 282:20151561.

Pelletier, F., T. Clutton-Brock, J. Pemberton, S. Tuljapurkar, and T. Coulson. 2007. The evolutionary demography of ecological change: linking trait variation and population growth. Science 315:1571-1574.

Pelletier, F., K. Moyes, T. H. Clutton-Brock, and T. Coulson. 2012. Decomposing variation in population growth into contributions from environment and phenotypes in an age-structured population. Proceedings of the Roval Society B 279:394-401.

Peters, R. H. 1986. The ecological implications of body size. Cambridge University Press, Cambridge.

Plard, F., J.-M. Gaillard, T. Coulson, A. J. M. Hewison, M. Douhard, F. Klein, D. Delorme, et al. 2015. The influence of birth date via body mass on individual fitness in a long-lived mammal. Ecology 96:1516-1528.

Proffitt, K. M., J. A. Cunningham, K. L. Hamlin, and R. A. Garrott. 2014. Bottom-up and top-down influences on pregnancy rates and recruitment of northern Yellowstone elk. Journal of Wildlife Management 78:1383-1393.
Rankin, J. D., and H. Kokko. 2007. Do males matter? the role of males in population dynamics. Oikos 116:335-348.

Ripple, W. J., and R. L. Beschta. 2006. Linking wolves to willows via risk-sensitive foraging by ungulates in the northern Yellowstone ecosystem. Forest Ecology and Management 230:96-106.

Ripple, W. J., T. M. Newsome, C. Wolf, R. Dirzo, K. T. Everatt, M. Galetti, M. W. Hayward, et al. 2015. Collapse of the world's largest herbivores. Science Advances 1:e1400103.

Romme, W. H., and M. G. Turner. 2015. Ecological implications of climate change in Yellowstone: moving into uncharted territory? Yellowstone Science 23:6-12.

Sæther, B.-E. 1997. Environmental stochasticity and population dynamics of large herbivores: a search for mechanisms. Trends in Ecology and Evolution 12:143-149.

Sæther, B.-E., and Ø. Bakke. 2000. Avian life history variation and contribution of demographic traits to the population growth rate. Ecology 81:642-653.

Savage, V. M., J. F. Gillooly, J. H. Brown, G. B. West, and E. L. Charnov. 2004. Effects of body size and temperature on population growth. American Naturalist 163:429-441.

Schindler, S., P. Neuhaus, J. M. Gaillard, and T. Coulson. 2013. The influence of nonrandom mating on population growth. American Naturalist 182:28-41.

Small, M. 2012. Dynamics of biological systems. CRC Mathematical and Computational Biology Series. CRC Press, Boca Raton, FL.

Smith-Ramesh, L. M., A. E. Rosenblatt, and O. J. Schmitz. 2018. Multivariate climate change can favor large herbivore body size in food webs. American Naturalist 191:333-342.

Starns, H. D., F. W. Weckerly, M. A. Ricca, and A. Duarte. 2015. Vegetation changes associated with a population irruption by Roosevelt elk. Ecology and Evolution 5:109-120.

Stenseth, N. C., K.-S. Chan, G. Tavecchia, T. Coulson, A. Mysterud, T. Clutton-Brock, and B. Grenfell. 2004. Modelling non-additive and nonlinear signals from climatic noise in ecological time series: Soay sheep as an example. Proceedings of the Roval Society B 271:1985-1993.

Stephens, P. A., I. L. Boyd, J. M. McNamara, and A. I. Houston. 2009. Capital breeding and income breeding: their meaning, measurement, and worth. Ecology 90:2057-2067.

Trebitz, A. S., K. L. Cottingham, and L. J. Jackson. 2000. An introduction to the practice of ecological modeling. BioScience 50:694-706.

Tredennick, A. T., B. J. Teller, P. B. Adler, G. Hooker, and S. P. Ellner. 2018. Size-by-environment interactions: a neglected dimension of species' responses to environmental variation. Ecologv Letters 21:1757-1770.

van Benthem, K. J., H. Froy, T. Coulson, L. L. Getz, M. K. Oli, and A. Ozgul. 2017. Trait-demography relationships underlying small mammal population fluctuations. Iournal of Animal Ecology 86:348-358.

van der Meer, J. 2006. Metabolic theories in ecology. Trends in Ecology and Evolution 21: 136-140.

Vetharaniam, I., D. R. Stevens, G. W. Asher, S. J. R. Woodward, J. A. Archer, and M. D. Rollo. 2009. A model of growth, pregnancy and lactation in the red deer. Journal of Agricultural Science 147:253272.

Via, S., R. Gomulkiewicz, G. De Jong, S. M. Scheiner, C. D. Schlichting, and P. H. Van Tienderen. 1995. Adaptive phenotypic plasticity: consensus and controversy. Trends in Ecology and Evolution 10:212-217. 
Visscher, D., E. Merrill, D. Fortin, and J. Frair. 2006. Estimating woody browse availability for ungulates at increasing snow depths. Forest Ecology and Management 222:348-354.

Vucetich, J. A., D. W. Smith, and D. R. Stahler. 2005. Influence of harvest, climate and wolf predation on Yellowstone elk, 19612004. Oikos 111:259-270.

Wagner, F. H. 2006. Yellowstone's destabilized ecosystem: elk effects, science and policy conflict. Oxford University Press, New York.

White, P. J., R. A. Garrott, J. J. Borkowski, J. G. Berardinelli, D. R. Mertens, and A. C. Pils. 2008. Diet and nutrition of central Yellowstone elk during winter. Pages 157-176 in R. A. Garrott, P. J. White, and F. G. R. Watson, eds. Terrestrial ecology. Elsevier, Amsterdam.

White, P. J., R. A. Garrott, K. L. Hamlin, R. C. Cook, J. G. Cook, and J. A. Cunningham. 2011. Body condition and pregnancy in northern Yellowstone elk: evidence for predation risk effects? Ecological Applications 21:3-8.

White, P. J., K. M. Proffitt, L. D. Mech, S. B. Evans, J. A. Cunningham, and K. L. Hamlin. 2010. Migration of northern Yellowstone elk: implications of spatial structuring. Iournal of Mammalogy 91:827-837.

Williams, J. L., T. E. X. Miller, and S. P. Ellner. 2012. Avoiding unintentional eviction from integral projection models. Ecology 93:2008-2014.

Williams, I. D., and N. V. C. Polunin. 2001. Large-scale associations between macroalgal cover and grazer biomass on middepth reefs in the Caribbean. Coral Reefs 19:358-366.

Associate Editor: Tom E. X. Miller Editor: Russell Bonduriansky

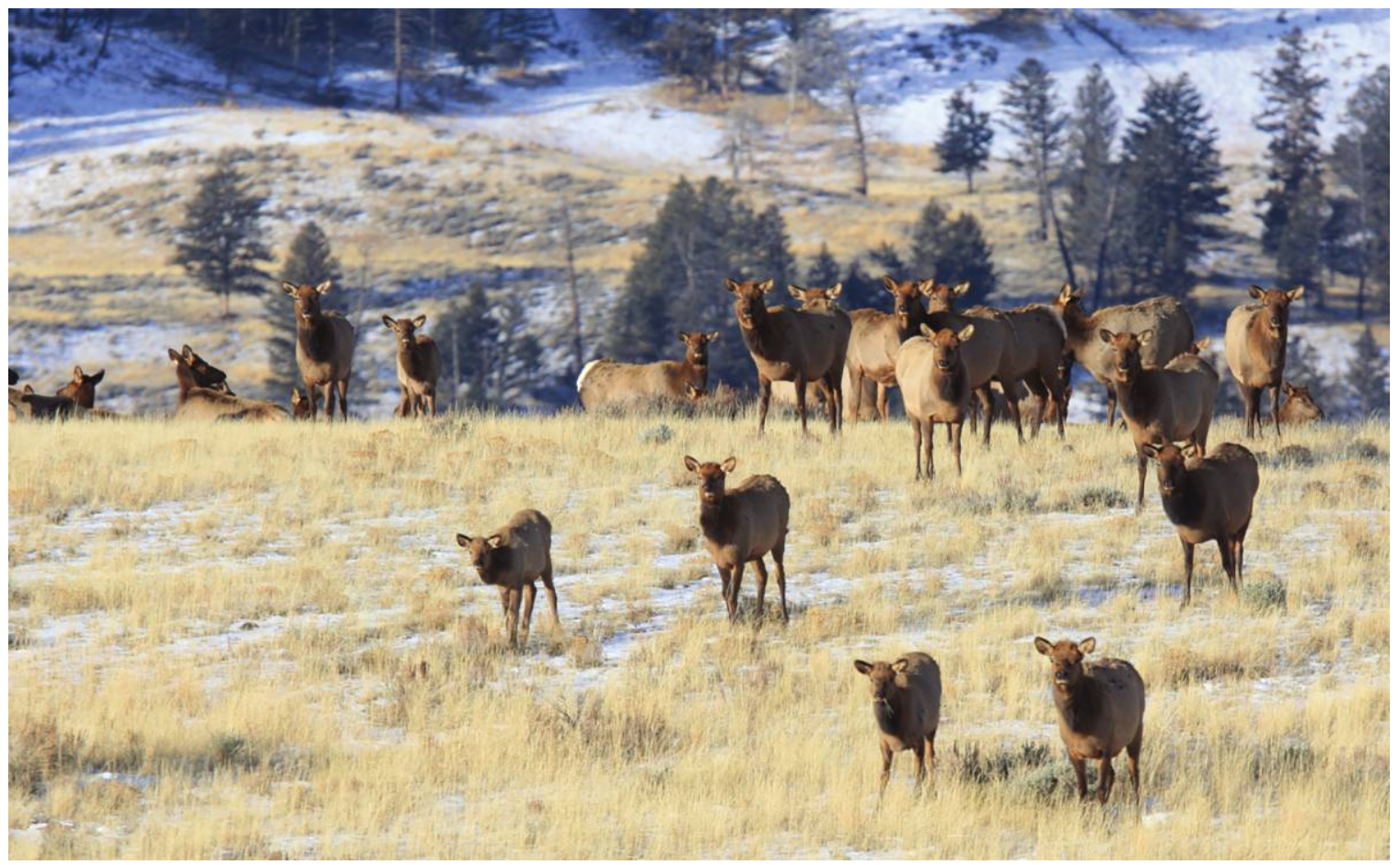

Elk in Yellowstone National Park. Photo credit: Daniel Stahler/NPS photo. 